\title{
New Specimens of the Pinnipediform Pteronarctos from the Miocene of Oregon
}

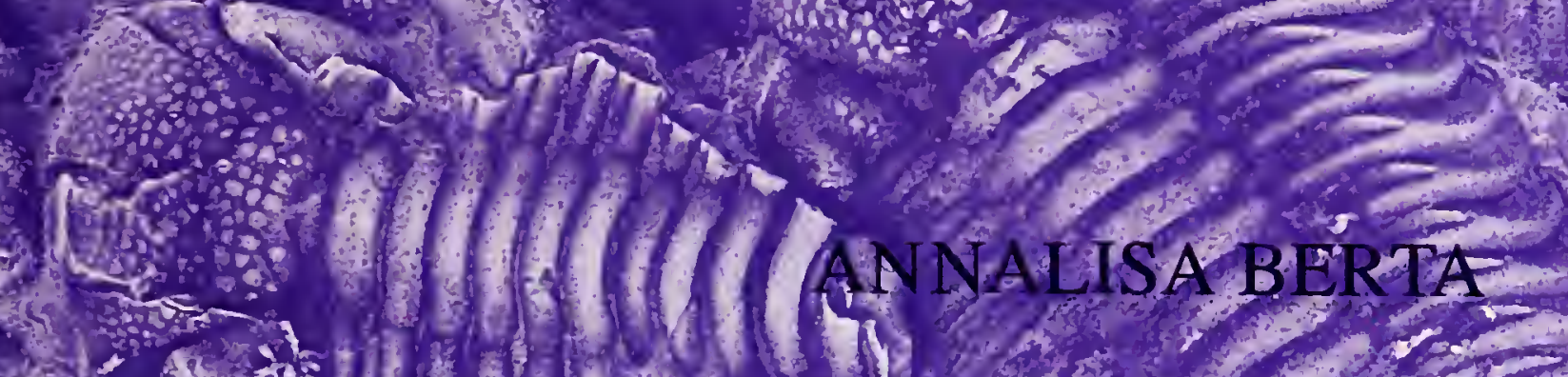

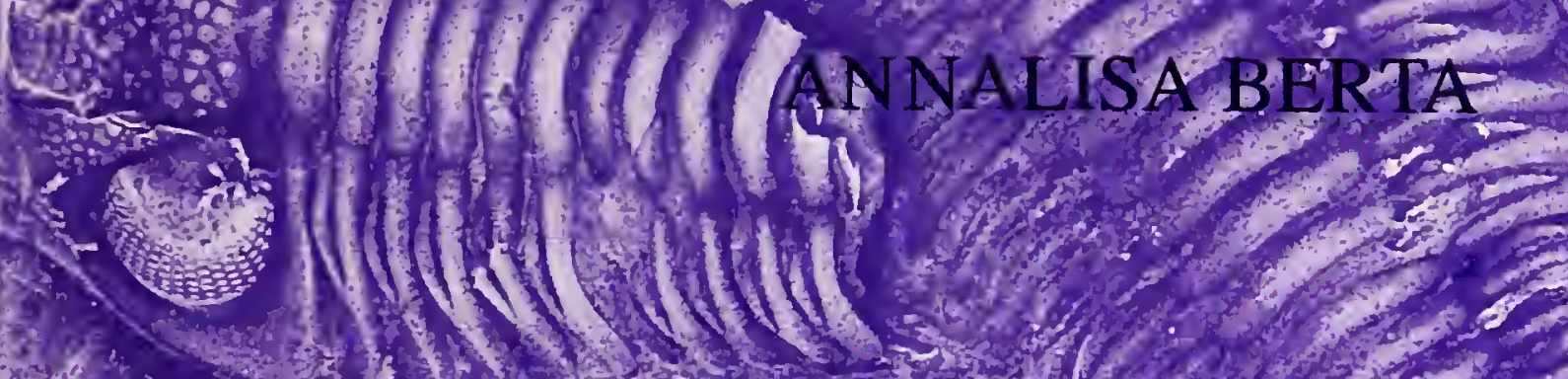




\title{
SERIES PUBLICATIONS OF THE SMITHSONIAN INSTITUTION
}

Emphasis upon publication as a means of "diffusing knowledge" was expressed by the first Secretary of the Smithsonian. In his formal plan for the institution, Joseph Henry outlined a program that included the following statement: "It is proposed to publish a series of reports, giving an account of the new discoveries in science, and of the changes made from year to year in all branches of knowledge." This theme of basic research has been adhered to through the years by thousands of titles issued in series publications under the Smithsonian imprint, commencing with Smithsonian Contributions to Knowledge in 1848 and continuing with the following active series:

\author{
Smithsonian Contributions to Anthropology \\ Smithsonian Contributions to Botany \\ Smithsonian Contributions to the Earth Sciences \\ Smithsonian Contributions to the Marine Sciences \\ Smithsonian Contributions to Paleobiology \\ Smithsonian Contributions to Zoology \\ Smithsonian Folklife Studies \\ Smithsonian Studies in Air and Space \\ Smithsonian Studies in History and Technology
}

In these series, the institution publishes small papers and full-scale monographs that report the research and collections of its various museums and bureaux or of professional colleagues in the world of science and scholarship. The publications are distributed by mailing lists to libraries, universities, and similar institutions throughout the world.

Papers or monographs submitted for series publication are received by the Smithsonian Institution Press, subject to its own review for format and style, only through departments of the various Smithsonian museums or bur eaux, where the manuscripts are given substantive review. Press requirements for manuscript and ant preparation are outlined on the inside back cover.

Robert McC. Adams

Secretary

Smithsonian Institution 
SMITHSONIAN CONTRIBUTIONS TO PALEOBIOLOGY $\bullet$ NUMBER 78

\section{New Specimens of the Pinnipediform Pteronarctos from the Miocene of Oregon}

Annalisa Berta

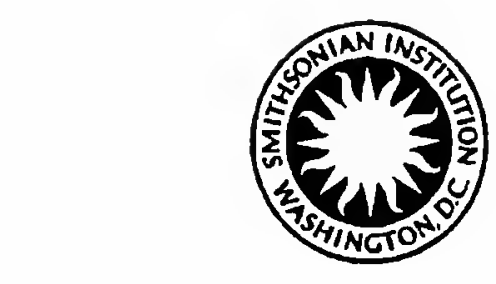

SMITHSONIAN INSTITUTION PRESS

Washington, D.C.

1994 


\section{A B S T R A C T}

Berta, Annalisa. New Specimens of the Pinnipediform Pteronarctos from the Miocene of Oregon. Smithsonian Contributions to Paleobiology, number 78, 30 pages, 21 figures, 1994. - New fossils of the pinnipediform Pteronarctos from the Miocene Astoria Formation of coastal Oregon provide more information on the cranial anatomy, interrelationships, and higher level phylogeny of this taxon. Additional skulls are referred to a previously described species, P. goedertae (Barnes, 1989). A previously named species, Pteronarctos piersoni (Barnes, 1990) is recognized as the junior synonym of $P$. goedertae. The genus Pacificotaria (Barnes, 1992) is synonymized with Pteronarctos. The genus Pteronarctos is removed from the "Enaliarctinae" (= "Enaliarctidae") and recognized as the sister group of the Pinnipedia (including Otariidae, Odobenidae, Allodesmus, Desmatophoca, Pinnarctidion, and Phocidae).

OfFICIAL PUBLICATION DATE is handstamped in a limited number of initial copies and is recorded in the Institution's annual report, Smithsonian Year. SERIES COVER DESIGN: The trilobite Phacops rana Green.

Library of Congress Cataloging-in-Publication Data

Berta, Annalisa.

New specimens of the pinnipediform Pteronarctos from the Miocene of Oregon / Annalisa Berta.

p. cm. - (Smithsonian contributions to paleobiology ; no. 78)

Includes bibliographical references.

1. Pteronarctos-Oregon. 2. Paleontology-Miocene. 3. Paleontology-Oregon. I. Title. II. Series. QE701.S56 no.78 [QE882.P5] 560 s-dc20 [569.74] 93-34257

(0) The paper used in this publication meets the minimum requirements of the American National Standard for Permanence of Paper for Printed Library Materials Z39.48-1984. 


\section{Contents}

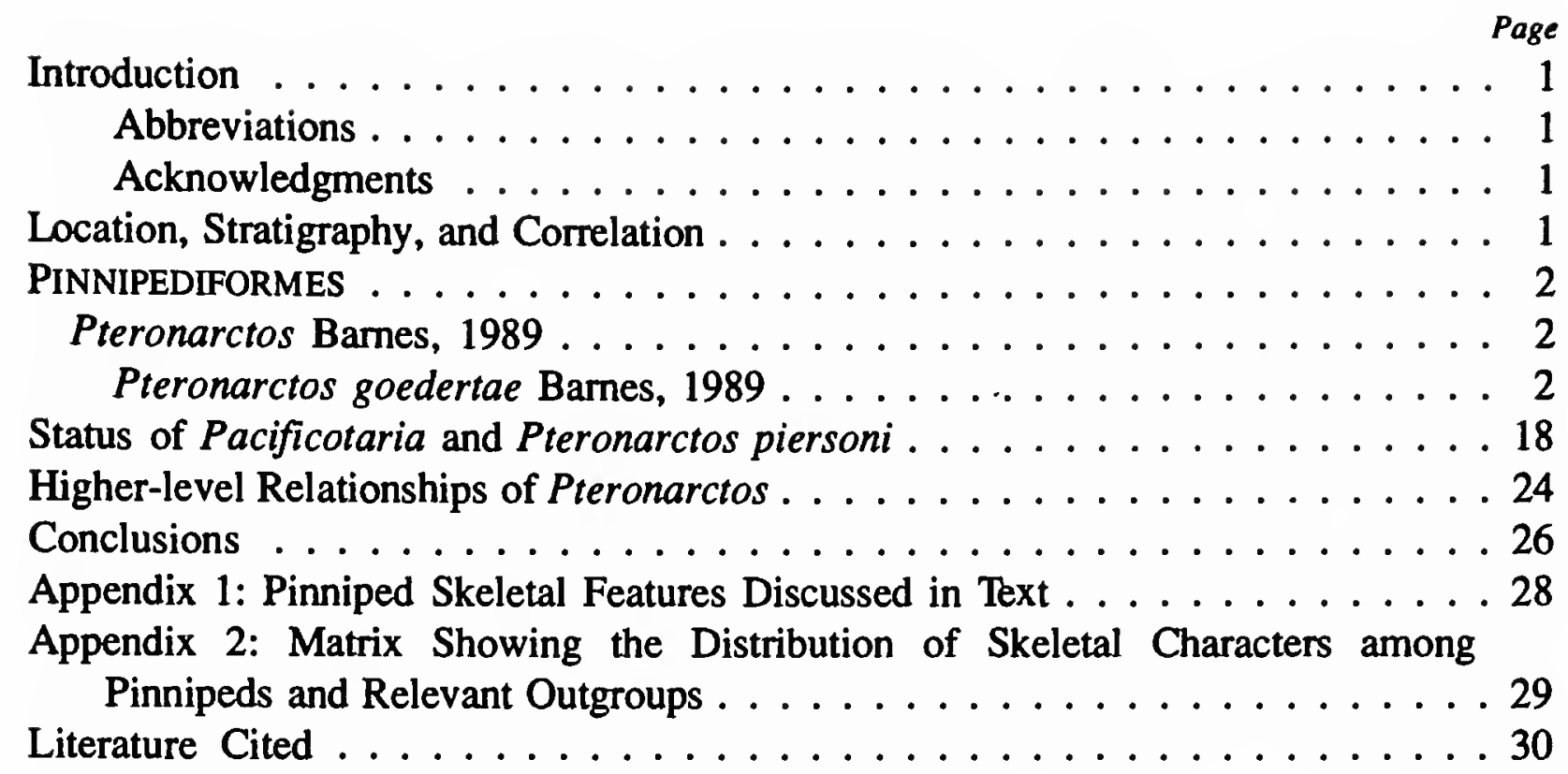





\title{
New Specimens of the Pinnipediform Pteronarctos from the Miocene of Oregon
}

\author{
Annalisa Berta
}

\section{Introduction}

The genus Pteronarctos was founded to include a single species $P$. goedertae known from the holotype skull from the Miocene Astoria Formation of coastal Oregon (Barnes, 1989). A second species, $P$. piersoni, was described by Barnes (1990) on the basis of two nearly complete skulls. Although $P$. piersoni was collected stratigraphically higher in the same formation as $P$. goedertae, it is regarded by Bames as having a more primitive cranial morphology than the former species and therefore not part of the same lineage. According to Bames $(1989,1990)$ Pteronarctos; which he placed in the subfamily "Enaliarctinae," is near the ancestry of the Otariidae. In his arrangement the Otariidae (= "Otarioidea") includes the following subfamilies: Enaliarctinae, Otariinae, Desmatophocinae, Allodesminae, Imagotariinae, Dusignathinae, and Odobeninae. According to Barnes, four genera, Pteronarctos, Pacificotaria, Pinnarctidion, and Enaliarctos, comprise the "Enaliarctinae," which he recognized as "a horizontal group, a grade rather than a clade..." (Barnes, 1987:19). As he further noted (Barnes, 1990, 1992) the "Enaliarctinae" (= "Enaliarctidae") is paraphyletic (see also Wyss, 1987; Berta, 1991; Berta and Wyss, in press).

I have previously proposed (Berta et al., 1989; Berta, 1991) the Pinnipedimorpha, comprising the ancestor of Enaliarctos and all its descendants (including phocids as well as "otarioids"), as the most inclusive pinniped taxon. The next most inclusive clade, here named the Pinnipediformes, includes Pteronarctos and all Pinnipedia (sensu stricto). I provide further evidence to support this view here. Pinnarctidion is recognized as a member of a more inclusive pinniped clade that includes also Allodesmus, Desmatophoca, odobenids, and

Annalisa Berta, Department of Biology, San Diego State University, San Diego, California, 92182 (Research Associate in the Department of Paleobiology, National Museum of Natural History, Smithsonian Institution). phocids as originally proposed by Wyss (1987) (see also Berta, 1991).

In this study I refer additional cranial and postcranial material from the Astoria Formation of coastal Oregon to a single species Pteronarctos goedertae and discuss the significance of this taxon with respect to the phylogeny of the Otariidae, as proposed by Barnes $(1989,1992)$ and to other pinnipeds.

ABBREVIATIONS.-The following institutional abbreviations are cited:

LACM Natural History Museum of Los Angeles County, Los Angeles, California

UCMP Museum of Paleontology, University of California, Berkeley, California

USNM National Museum of Natural History, Smithsonian Institution, Washington, D.C.

ACKNOWLEDGMENTS.-Specimen preparation was done by Ed Peterson (American Museum of Natural History) and Michael Tiffany (National Museum of Natural History). Line drawings were prepared by Christi Endres (Figure 6) and Matthew Colbert (Figures 3, 4). For specimen photography I thank Sharon Messenger. Andre Wyss provided the photomicrographs.

I am grateful to Lawrence G. Barnes (Natural History Museum of Los Angeles County) for providing casts of comparative specimens. I thank L.G. Barnes, Clayton E. Ray, and Charles Potter (National Museum of Natural History) for access to specimens used in this study. This research was supported by NSF grants BSR 8607061 and BSR 9006535.

\section{Location, Stratigraphy, and Correlation}

New material of Pteronarctos is all from sediments referred to as the Astoria Formation near Newport, Lincoln County, 
Oregon. As reviewed by Barnes $(1989,1990)$ the type Astoria Formation exposed at Astoria, Oregon, includes rocks of late early Miocene age. This formational name has been applied to slightly younger rocks (late early Miocene to early middle Miocene) farther south along the Oregon coast in the Newport embayment.

The holotype of Pteronarctos goedertae was collected from a horizon just above the base of the Astoria Formation, where it contacts the underlying Nye Mudstone (Bames, 1989). The molluscan fauna from this locality has been assigned the Newportian Molluscan Stage (Armentrout, 1981), which is correlated with the Saucesian Foraminiferal Stage (Addicott, 1976; Moore, 1963). Land mammals collected from a higher part of the Astoria Formation (see below) have been correlated with the Hemingfordian or early Barstovian Land Mammal age, approximately 19-15 Ma. The stratigraphic provenance of the holotype near the base of the Astoria Formation led Bames to suggest that this specimen was probably close to $19 \mathrm{Ma}$.

According to Bames (1990) the holotype and paratype of Pteronarctos piersoni were collected from a concretionary horizon, "Iron Mountain bed," within the Astoria Formation. This same stratigraphic unit has produced a chalicothere cranium referred to Tylocephalonyx sp. (Coombs, 1979; Munthe and Coombs, 1979) with an estimated age of between 15 and $16 \mathrm{Ma}$. Since the holotype and paratype of Pteronarctos piersoni were found from a horizon that is stratigraphically high within the stratotype of the Newportian Stage, the age of the specimens is estimated at $16 \mathrm{Ma}$, and correlated with the Hemingfordian or early Barstovian Land Mammal Age (Barnes, 1990).

The seven specimens of Pteronarctos goedertae described in this report were all collected by Douglas Emlong in the area around Newport, Lincoln County, Oregon. Four skulls USNM 206274, USNM 250282, USNM 335695, and USNM 250320 were collected from the "Iron Mountain Bed" in the Astoria Formation. A skull and associated jaw, USNM 167648, a skull and mandibles and associated postcrania, USNM 335432, and a skull, USNM 250323, came from an unspecified horizon within the Astoria Formation.

\section{PinNipediformes}

This taxon includes Pteronarctos, Otariidae, Odobenidae, Allodesmus, Desmatophoca, Pinnarctidion, and Phocidae.

DEFINITION. - The most recent common ancestor of Pteronarctos and all of its descendants.

DIAGNOSIS.-Pinnipediformes are distinguished by the following synapomorphies: maxilla makes a significant contribution to the anterior orbital wall; lacrimal fused early in ontogeny to maxilla and frontal, greatly reduced or absent; prominent nasal processes of premaxilla that protrude anterior and dorsal to alveolar margin; mastoid process close to paroccipital process, the two connected by a high, continuous ridge; shallow or absent embrasure pit on palate between $\mathrm{P}^{4}$ and $\mathbf{M}^{1}$.

COMMENTS.-Berta (1991) originally recognized this clade as an unnamed group comprising the most recent common ancestor of Pteronarctos and the Pinnipedia. Barnes' (1989, 1990) arrangement differs in his recognition of Pteronarctos as an "enaliarctine" within the family "Otariidae." As discussed elsewhere (Berta, 1991; Berta and Wyss, in press) both the "Enaliarctinae" and the "Otariidae" (sensu Barnes, 1989, 1990, 1992) are non-monophyletic groups.

\section{Pteronarctos Barnes, 1989}

Pteronarctos Bames, 1989:3.

Pacificotaria Barnes, 1992:3.

TYPE SPECIES.-Pteronarctos goedertae Barnes, 1989.

INCLUDED SPECIES.-Pteronarctos goedertae Bames, 1989, $P$. piersoni (Barnes, 1990) as a junior synonym of $P$. goedertae, and Pacificotaria hadromma (Barnes, 1992).

REVISED DIAGNOSIS OF GENUS.-Supraorbital processes slightly enlarged; $\mathrm{P}^{3}$ with bilobed posterior root; $\mathrm{P}^{4}$ with protocone root fused to posterolateral root; short lower cheek tooth row.

COMMENTs.-The original description of Pteronarctos (Bames, 1989) was based on characters most of which are now identified at a more general level (see Relationships).

\section{Pteronarctos goedertae Barnes, 1989}

FIGURES 1-20

Pteronarctos goedertae Barnes, 1989:3, figs. 1-6, 7c.

Pteronarctos piersoni Barnes, 1990:2, figs. 1-9, 10a, 11a, 12a.

Pacificotaria hadromma Barnes, 1992:4, figs. 1-6, 7a, 8a, 9a.

EMENDED DIAGNOSIS.-As for the genus.

TYPE.-Holotype: LACM 123883, complete skull with right $\mathrm{I}^{3}$ and both canines.

TYPE LOCALITY.-As described by Barnes (1989) from basal part of Astoria Formation, LACM locality 5058, Jumpoff Joe, north end of Nye Beach, Newport, Lincoln County, Oregon; collected by Gail H. Goedert, 18 April 1981.

REFERRED SPECIMENS.-LACM 127972 (holotype of $P$. piersoni), complete skull with canines, found by Guy $\mathrm{L}$. Pierson, 2 April 1983, among loose boulders on Moolack Beach between the mouths of Schooner Creek and Moolack Creek, Lincoln County, Oregon.

LACM 128002 (paratype of $P$. piersoni), complete cranium with left $\mathrm{P}^{4}$, found among loose boulders on the beach on the north flank of Schooner Point, just north of the mouth of Schooner Creek, Lincoln County, Oregon.

LACM 127973, complete skull with all teeth except left $\mathrm{I}^{3}$ and right and left $\mathrm{M}^{1-2}$ collected by Guy E. Pierson, 26 April 1983, from locality LACM 4851, as described by Barnes (1992), among loose boulders on Moolack Beach between the 

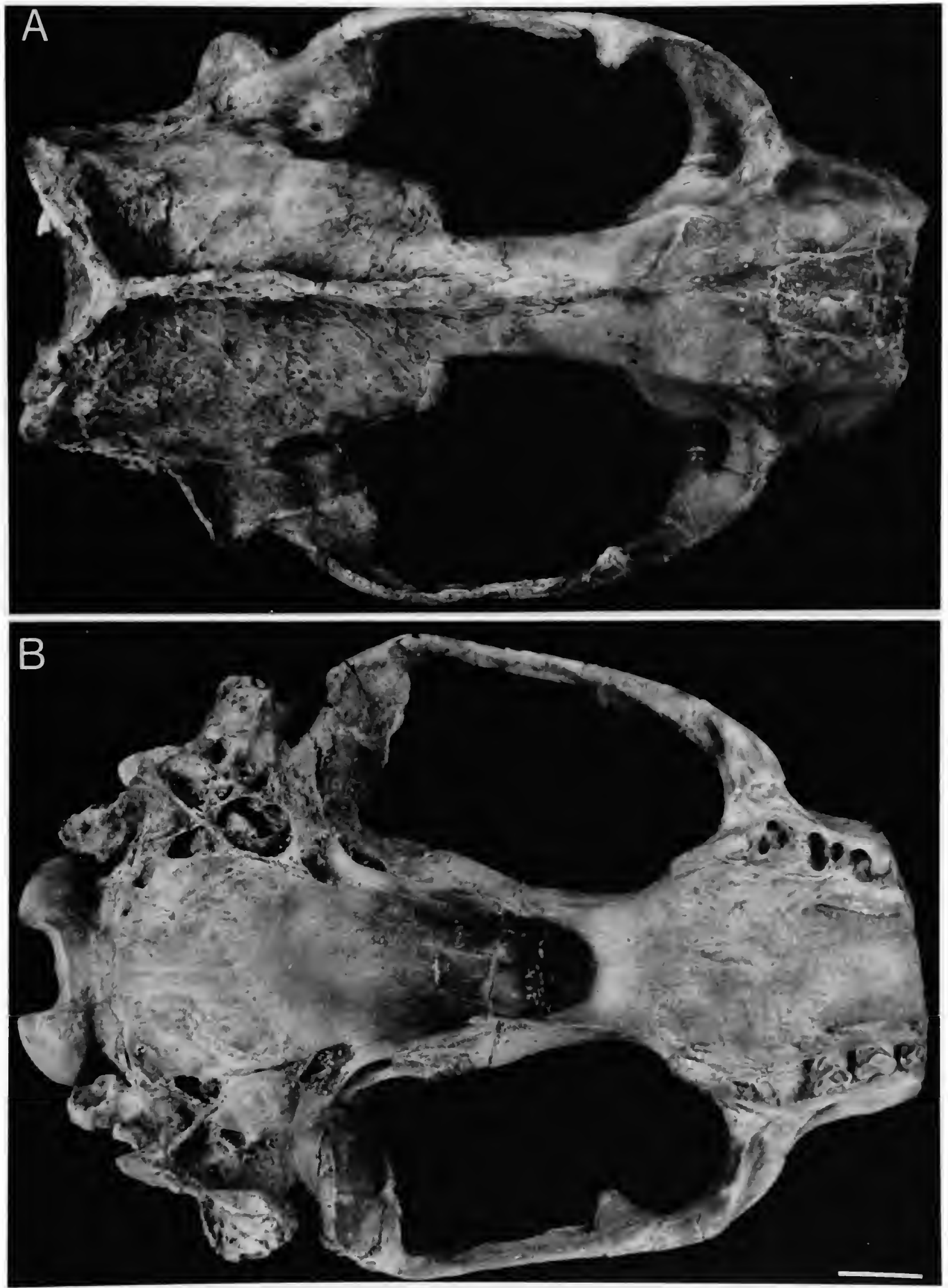

FIGURE 1.-Pteronarctos goedertae, USNM 335432, referred male, skull: A, dorsal view; B, ventral view. (Scale $=2 \mathrm{~cm}$.) 


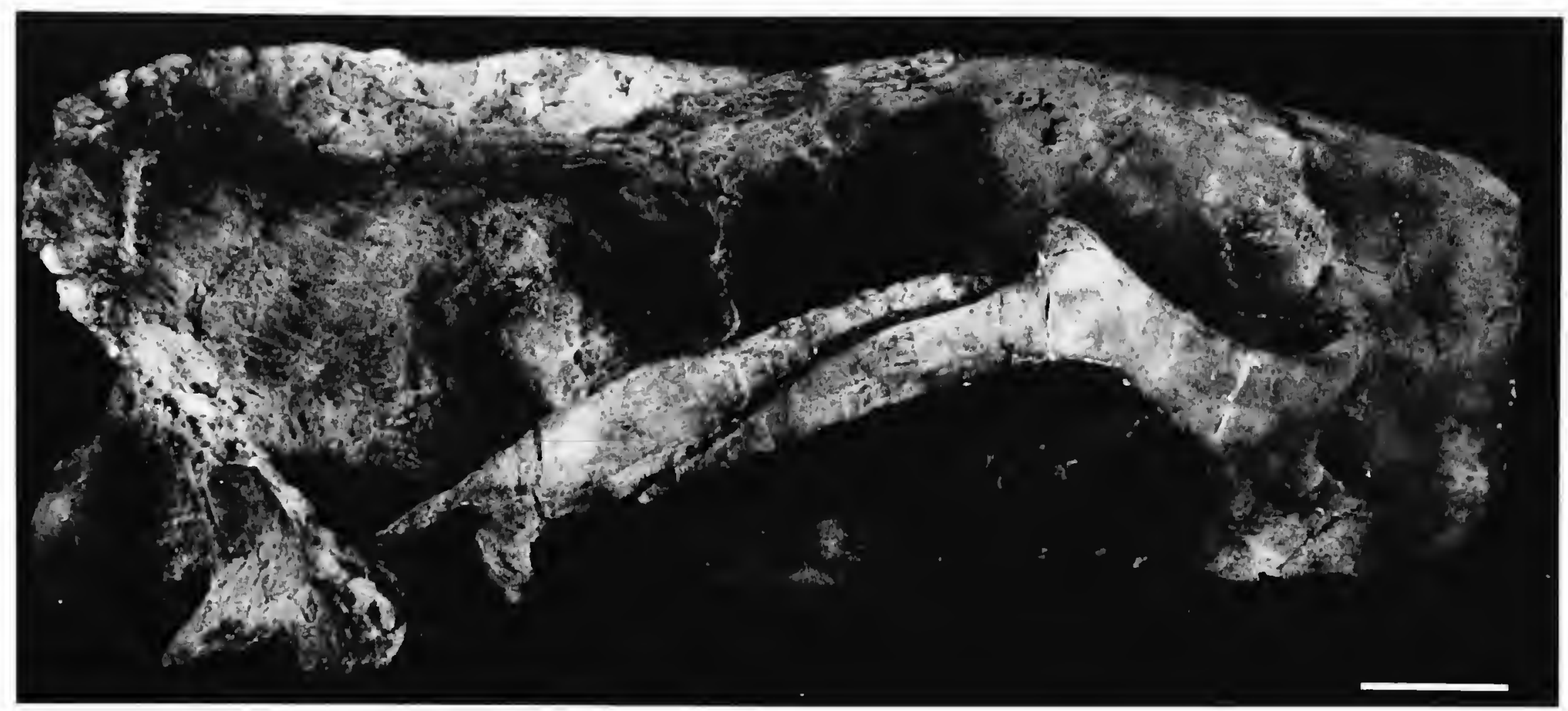

FIGURE 2.-Pteronarctos goedertae, USNM 335432, referred male, skull: lateral view. (Scale $=2 \mathrm{~cm}$.)

mouths of Schooner Creek and Moolack Creek, Lincoln County, Oregon, in "Iron Mountain bed", Astoria Formation.

USNM 335432 (E-547), skull lacking rostrum, associated mandibular rami, and probably from the same individual, atlas, axis, a lumbar vertebra, 3 thoracic vertebrae, right scapula, and right proximal humerus, collected by Douglas Emlong, April 1969, from north of Beverly Beach, about 300 yds [100 m] south of Spencer Creek and $200 \mathrm{ft}[60 \mathrm{~m}$ ] out from bank, Lincoln County, Oregon. SW $1 / 4, \mathrm{SE}^{1 / 4}$, Sec. 5, T. $10 \mathrm{~S}, \mathrm{R} .11$ W, Yaquina Quadrangle, 15 minute series, USGS; in large concretion, Astoria Formation.

USNM 250282 (E-255), skull lacking rostrum and teeth, collected by Douglas Emlong, 1961, approximately 3/4 mi [1.2 $\mathrm{km}$ ] north of Yaquina Head Lighthouse, Lincoln County, Oregon. $\mathrm{NW}^{1} / 4, \mathrm{NW}^{1} / 4$, Sec. 20 , T. $10 \mathrm{~S}, \mathrm{R} .11 \mathrm{~W}$, Yaquina Quadrangle, 15 minute series, USGS; in drift concretion in "Iron Mountain bed", Astoria Formation.

USNM 335695 (E-51), skull, collected by Douglas Emlong, Spring, 1961, about $1 \mathrm{mi}$ [1.6 km] NNW of Agate Beach, Lincoln County, Oregon, in concretion in drift in "Iron Mountain bed", Astoria Formation.

USNM 167648 (E-548), skull with canines and $\mathrm{P}^{3}$ and right mandible with $\mathrm{C}, \mathrm{P}_{2-4}, \mathrm{M}_{1}$, collected by Gordon Bittner, March 1968 , from a slide on the cliff near high tide line, about $1 / 4$ mile [400 m] north of Moolack Beach State Park near a prominent sandstone outcrop, Lincoln County, Oregon. NW1/4, Sec. 17, T. 10 S, R. 12 W, Yaquina Quadrangle, 15 minute series, USGS.

USNM 206274 (E-584), skull missing anterior portion of rostrum with right $\mathrm{P}^{3}$, collected by Douglas Emlong, from just south of Moolack Beach State Park, Lincoln County, Oregon.
$\mathrm{SE}^{1 / 4}, \mathrm{NW}^{1 / 4}$, Sec. 17, T. $10 \mathrm{~S}$, R. $11 \mathrm{~W}$, Yaquina Quadrangle, 15 minute series, USGS.

USNM 250320 (E-47), nearly complete skull, from $1 \mathrm{mi}$ [1.6 km] NNW of town of Agate Beach, collected by Douglas Emlong, 1/4 mi [400 m] north of mouth of Schooner Creek, Lincoln County, Oregon. NW'/4, NW $1 / 4$, Sec. 20, T. 10 S, R. 11 W, Yaquina Quadrangle, 15 minute series, USGS; in special concretion in drift in "Iron Mountain bed", Astoria Formation.

USNM 250323 (E-583), crushed skull with $\mathrm{P}^{4}$ and right $\mathrm{I}^{1}$, collected by Douglas Emlong, from $250 \mathrm{ft}$ [75 m] north of the mouth of Schooner Creek, in situ in cliff approximately $1 / 2 \mathrm{mi}$ [800 m] north of Yaquina Head, Lincoln County, Oregon.

DESCRIPTION.-Male and female adult and subadult individuals of Pteronarctos goedertae are represented in the Emlong collection. The following composite description is based on this material.

Adult Male: Four skulls are identified as adult males. USNM 335432, is a partial skeleton with a well preserved skull, right and left mandibles, and associated postcranial elements (Figures 1-10). The skull is missing the snout from the anterior root of $\mathrm{P}^{3}$ forward. The specimen is a young adult as judged by the pattern of suture closure ( 4 out of the 9 sutures listed by Sivertsen, 1954, are fully closed) and well worn dentition. USNM 250282 is missing the snout from $\mathrm{P}^{2}$ forward; all sutures are fused and the surface of the skull is water worn (Figures 11, 12). USNM 335695 lacks the snout from $\mathbf{P}^{3}$ forward. USNM 167648 is a skull with both canines and $\mathrm{P}^{3}$ and a right mandible with $\mathrm{C}, \mathrm{P}^{2-4}$, and $\mathrm{M}^{1}$ (Figures 13-15). Weathering has removed much of the right ear region and occiput and heavily abraded the left paroccipital and mastoid regions and tympanic bulla. 

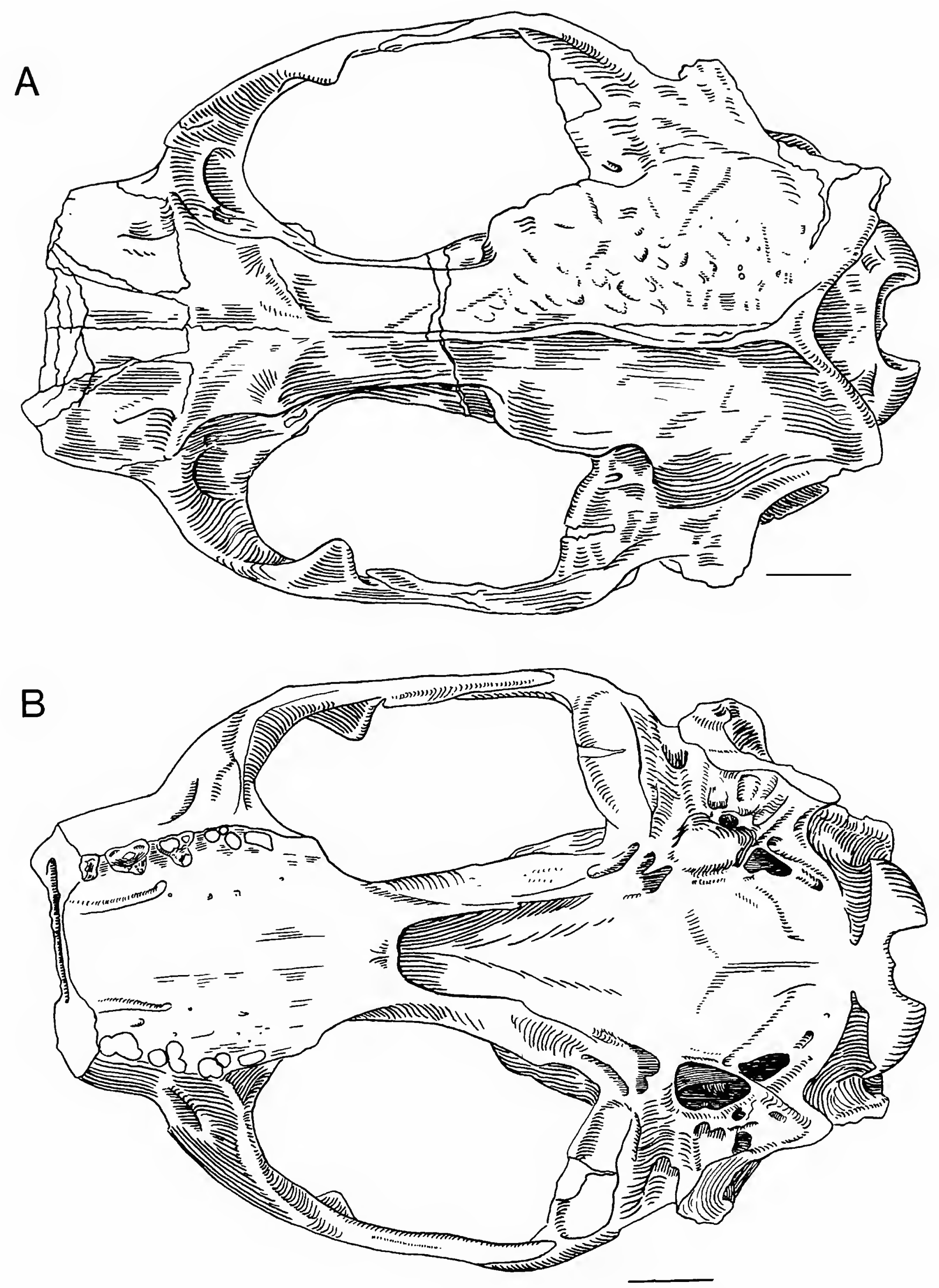

FIGURE 3.-Pteronarctos goedertae, USNM 335432, referred male, skull: A, dorsal view; B, ventral view. (Scale $=$ approximately $2 \mathrm{~cm}$.) 


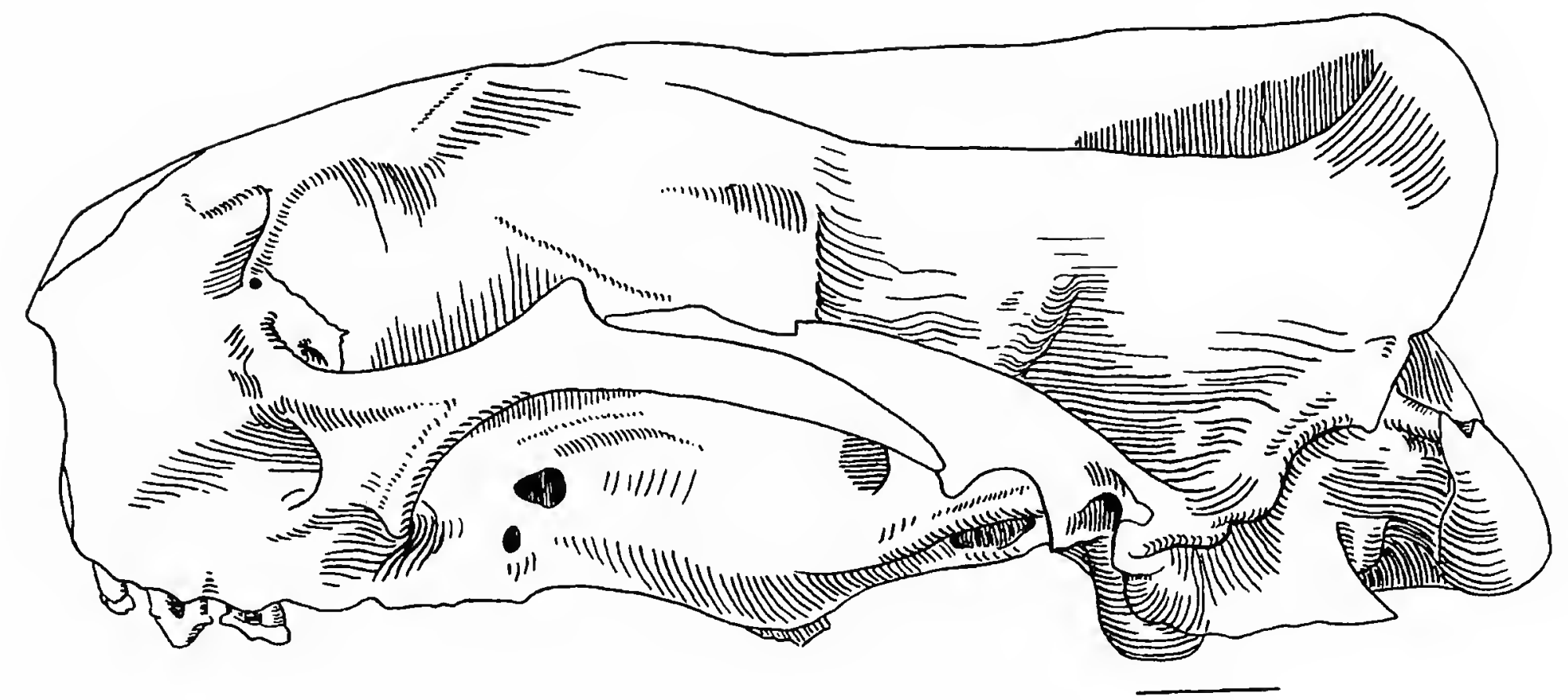

FIGURE 4.-Pteronarctos goedertae, USNM 335432, referred male, skull, lateral view. (Scale = approximately $2 \mathrm{~cm}$.)
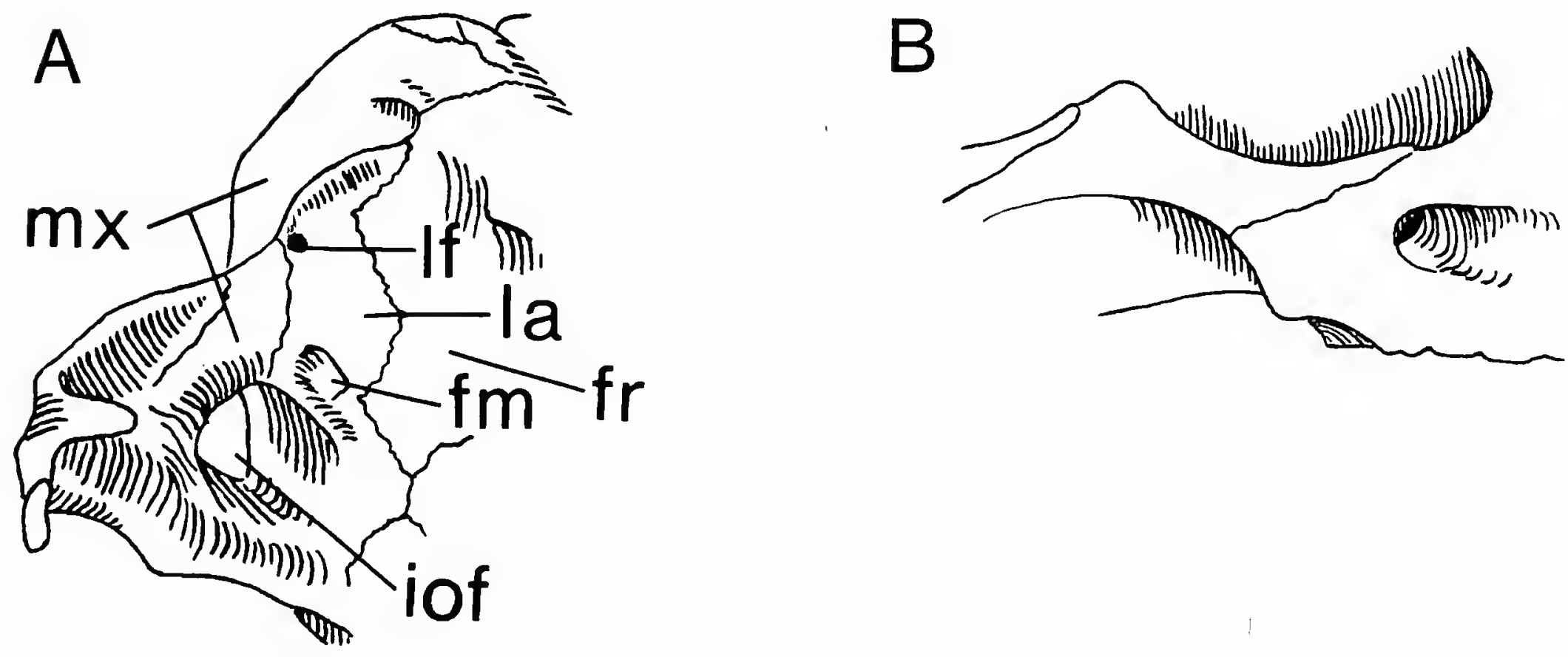

FIGURE 5.-Pteronarctos goedertae, A, USNM 335432, referred male: skull, diagram of orbital region ( $\mathrm{fm}=$ fossa muscularis; $\mathrm{fr}$ = frontal; iof = infraorbital foramen; la = lacrimal; lf = lacrimal foramen; $m x$ = maxillary); B, USNM 335695, referred male, skull, diagram of maxillary-jugal suture. (Not to scale.) 
These skulls differ from the holotype of Pteronarctos goedertae, LACM 127972, in being deeper dorsoventrally with prominent sagittal and lambdoidal crests well elevated above the braincase, especially USNM 335432 (Figures 1-4). In the only male individual with a snout preserved, USNM 167648 , the rostrum broadens across the canines (Table 1). The tip of the premaxilla is pointed and protrudes above the incisor alveoli. A strongly developed fossa is present on the rostrum between the roots of $\mathrm{I}^{3}$. Although this fossa was described as a unique feature of this taxon by Barnes (1992:5) it is also present in Enaliarctos (where it is especially well developed in $E$. barnesi (Berta, 1991, fig. 11)). The nasolabialis fossa is pronounced and its dorsal margin is produced into an antorbital process on the right side in USNM 167648.

The shape of the anterior narial opening is broad, deep, and ovoid in anterior view. As seen in dorsal view, the nasals are relatively long, narrow, and flared at their anterior termination. The posterior margin of the nasals is truncated at its contact with the frontal. The arrangement of these bones differs in the holotype of Pteronarctos goedertae, LACM 127929, and LACM 128002 in which a small sliver of the frontals extends anteriorly between the nasals (see Barnes, 1989, fig. 2; 1990, fig. 3). In USNM 250282 the snout region is separated and vertically offset from the remaining skull making it impossible to determine with certainty the relationship between the nasals and frontals. This region is not well preserved in USNM 335695. Anterior to the orbital rim is the nasolabialis fossa, especially well developed in USNM 335432 and USNM 335695 , in which the anterodorsal margin of this fossa forms a strong ridge. In the holotype of $P$. goedertae the nasolabialis fossa is shallow and lacks a dorsal ridge.

The interorbital region is long, narrow, and elevated above the braincase. Supraorbital processes are inflated tuberosities positioned at the anterior end of the interorbital area. The braincase is narrow anteriorly with square anterolateral margins. It broadens posteriorly and achieves maximum breadth behind the zygomatic arch. On its lateral surface at the level of the squamosal is a deep pseudosylvian sulcus.

The exoccipital portion of the occipital shield is completely preserved in USNM 335432 and USNM 335695 where it is well elevated above the braincase. The ventral border of the shield just above the occipital condyles is strongly concave. The medial margins of the occipital condyles are nearly parallel. Within the foramen magnum and directed anteriorly and laterally is a large, ovoid condyloid foramen.

The zygomatic arch is bowed laterally, narrowing slightly at its anterior termination. The ventral portion of the arch joins the palate opposite $\mathbf{M}^{2}$ at a nearly horizontal plane. The ventral surface of the arch below the infraorbital foramen is marked by a well developed fossa at its base. The posterior process of the jugal curves dorsally and medially and cups the enlarged circular orbits. The maxillary-jugal suture can be traced best in USNM 335695 where it lies along the medial surface of the jugal extending from the dorsal edge of the anterior process to a point on the posterior process where it turns and extends anteriorly near the base of the process. The maxillary and jugal as described above make a V-shaped contact (Figure 5). The postorbital process of the jugal is large and strongly inclined medially. The narrow anterior tip of the zygomatic process of the squamosal begins a short distance behind the postorbital process of the jugal and it is separated from the braincase by a broad shallow fossa. The preglenoid process is large and well developed especially the dorsolateral margin. There is no postglenoid foramen although there is a crease along the

TABLE 1.-Cranial measurements (mm) of Pteronarctos goedertae from coastal Oregon (e = estimated).

\begin{tabular}{|c|c|c|c|c|c|}
\hline Measurements & $\begin{array}{c}\text { Adult male } \\
\text { USNM } 335432\end{array}$ & $\begin{array}{c}\text { Adult male } \\
\text { USNM } 250282\end{array}$ & $\begin{array}{c}\text { Adult male } \\
\text { USNM } 167648\end{array}$ & $\begin{array}{c}\text { Adult female } \\
\text { USNM } 206274\end{array}$ & $\begin{array}{l}\text { Subadult female } \\
\text { USNM } 250320\end{array}$ \\
\hline 1. Skull length (CBL) & & & 235.0 & & 175.29 \\
\hline 2. Greatest width at anterior nares & $34.44^{e}$ & & 32.27 & & 22.71 \\
\hline 3. Width across antorbital processes & 60.42 & & 60.09 & & 29.72 \\
\hline 4. Least width across interorbital constriction & 26.82 & 23.34 & 27.99 & 23.89 & 20.77 \\
\hline 5. Width across supraorbital processes & 40.01 & 42.59 & 42.88 & $37.50^{e}$ & 24.24 \\
\hline 6. Width of braincase at anterior edge of glenoid fossa & 63.74 & 72.73 & 71.55 & $65.37 \mathrm{e}$ & 64.80 \\
\hline 7. Postpalatal length (postpalatal notch to basion) & 117.25 & $111.94^{e}$ & 111.87 & 103.97 & 84.17 \\
\hline 8. Width of rostrum across canines & & & 55.34 & & 34.38 \\
\hline 9. Zygomatic width & 143.95 & 133.44 & $121.60^{\circ}$ & & 96.18 \\
\hline 10. Auditory width & 115.34 & 108.54 & $109.48^{\mathrm{e}}$ & 102.74 & 70.63 \\
\hline 11. Mastoid width & 126.79 & $121.16^{\mathrm{e}}$ & $110.10^{c}$ & $122.50^{\circ}$ & 75.54 \\
\hline 12. Width of zygomatic root of maxilla & 12.12 & 13.68 & 13.89 & 12.61 & 13.11 \\
\hline 13. Basion to anterior edge of zygomatic root & 167.95 & $154.15^{e}$ & $152.55^{\mathrm{e}}$ & 146.91 & 115.89 \\
\hline 14. Width of palate across anterior root of $\mathrm{P}^{4}$ & $58.05^{\mathrm{e}}$ & 56.94 & 48.56 & $49.23^{e}$ & 36.42 \\
\hline 15. Width between infraorbital foramen & 61.10 & $62.54^{e}$ & 49.76 & 57.22 & $41.64^{e}$ \\
\hline 16. Greatest width across occipital condyles & 50.63 & & & & 43.92 \\
\hline 17. Greatest width of foramen magnum & 20.92 & & 22.68 & $20.66^{e}$ & $19.24^{e}$ \\
\hline 18. Greatest height of foramen magnum & 14.71 & & 14.43 & & $14.33^{\mathrm{e}}$ \\
\hline 19. Transverse diameter of infraorbital foramen & 11.66 & 9.54 & 6.89 & 8.75 & 11.16 \\
\hline 20. Length of tooth row, $C-M^{2}$ & & & 76.19 & $67.84^{e}$ & 59.35 \\
\hline
\end{tabular}




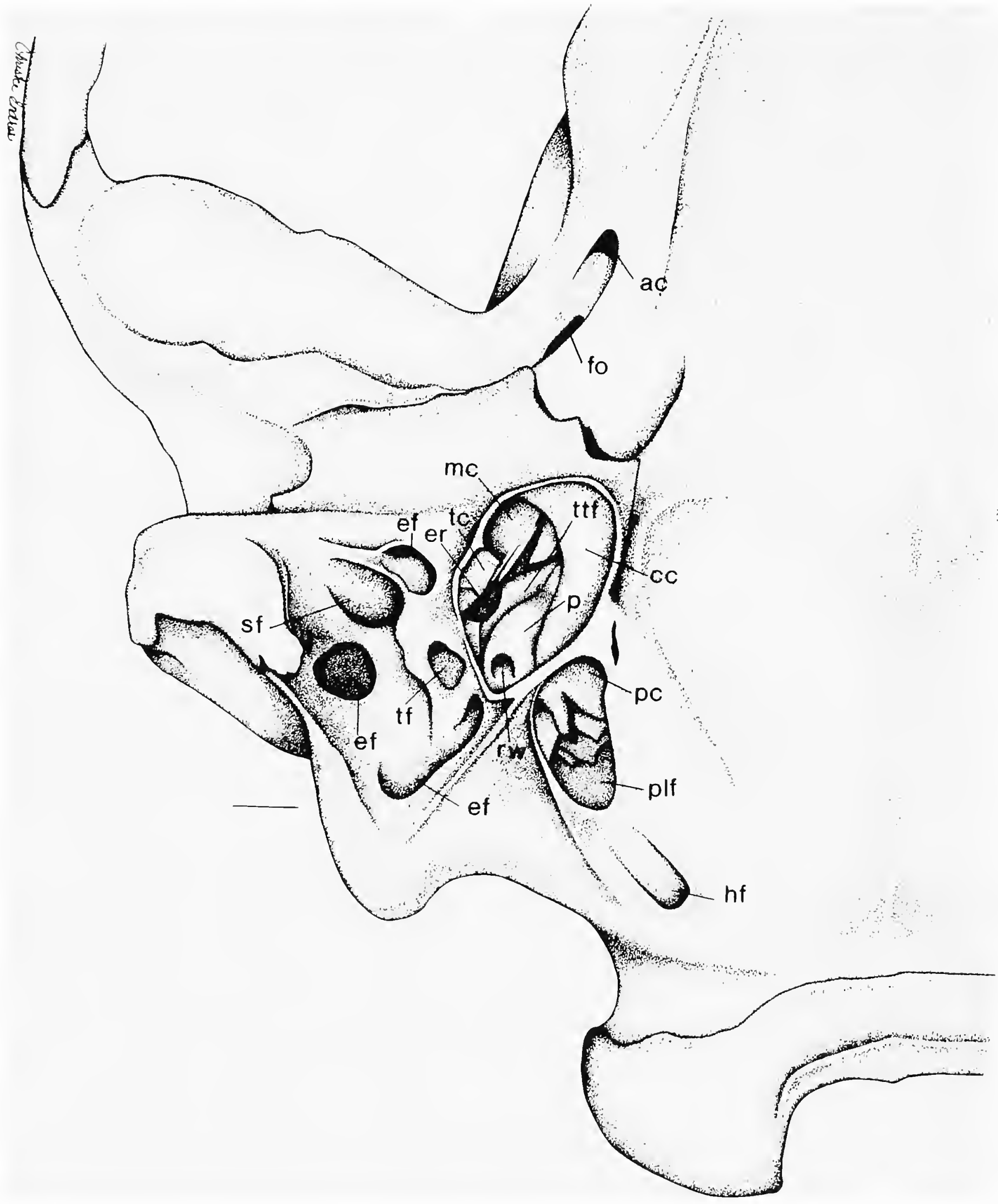

FIGURE 6.-Pteronarctos goederiae, referted male, USNM 335432, skull, ventral view of right side of basicranium with ventral wall of bulla removed $(\mathrm{ac}=$ posterior opening of alisphenoid canal; $\mathrm{cc}=$ ventral wall of carotid canal; ef = exocccipital fossa; er = epitympanic recess; fo = foramen ovale; $h f=$ hypoglossal foramen; $\mathrm{mc}$ = septum of musculotubarius canal; $\mathrm{p}=$ promontorium; $\mathrm{pc}=$ posterior opening of carotid canal; $\mathrm{plf}=$ posterior lacerate foramen; $\mathrm{rw}=$ round window; $\mathrm{sf}=$ stylomastoid foramen; $\mathrm{tc}=$ tympanic crest; $\mathrm{tf}=$ tympanohyal fossa; $\mathrm{ttf}=$ tensor tympani fossa). (Scale is approximately $5 \mathrm{~mm}$.) 
contact between the bulla and postglenoid process. At the median end of this crease is a small, slit-like opening, presumably the canal for the chorda tympani.

The medial wall of the orbit is formed by a broad plate of the frontal. The frontal in this region is bounded anteriorly by the lacrimal and ventrally by the maxilla and orbitosphenoid (Figure 5). No orbital vacuities are developed. The lacrimal is well preserved in USNM 335432. The bone is roughly rectangular with a large, circular lacrimal foramen positioned at the base of a well defined antorbital process. The orbital face of the lacrimal contacts the maxilla and frontal along a suture that appears to extend along the anterior side of the antorbital process adjacent to the nasolabialis fossa.

The infraorbital foramen is large and nearly circular in cross-section. The ventral floor of this opening is formed of a slightly sloped horizontal plate of the maxilla. Within the infraorbital canal in the wall of the maxilla at the base of the posterior root of the maxilla is positioned a small, blind elliptical opening preserved in USNM 335432. At the maxillary-lacrimal suture and just medial to the anterior rim of the infraorbital foramen is a deep, ovoid pit for the inferior oblique muscles.

The palatine is a relatively large, rectangular bone. Positioned behind the palatine-maxillary junction is a large sphenopalatine foramen. Anteroventral to this foramen is a smaller elliptical opening, the posterior palatine foramen. The orbitosphenoid is an elongated, narrow strip of bone bounded anteriorly by the frontal and maxilla, ventrally by the palatine, and posteriorly by the alisphenoid. The circular optic foramen is positioned just below the middle of the braincase. Posteroventral to the optic foramen is the anterior lacerate foramen. Enclosed in a common opening in the lateral wall of the anterior lacerate foramen and separated from it by a septum is the foramen rotundum.

The palate is slightly arched anteriorly, becoming nearly flat at its posterior termination. USNM 167648 differs in having a more strongly arched palate. The palate is widest at the level of $\mathrm{M}^{1}$ and narrows behind this tooth. A horizontal flange of the maxilla, the palatine process, extends a short distance behind $\mathbf{M}^{2}$. The incisive foramina preserved only in USNM 167648 are large paired openings, they do not not extend as far posteriorly as in the holotype. The anterior palatine foramen and associated sulcus originates medial to $\mathrm{P}^{4}$ and extend to the anterior root of $\mathrm{P}^{4}$; the latter observable only on USNM 167648. Several smaller foramina are located posterior to the anterior palatine sulcus on USNM 335432. The posterior emargination of the palate is U-shaped and smooth.

The palatine, pterygoid, and alisphenoid form an inflated strut between the palate and the braincase. This strut has a rounded margin anteriorly that is compressed posteriorly to form a sharp entopterygoid crest laterally that converges at the alisphenoid canal. Behind the pterygoid and alisphenoid canal the palatine, presphenoid, and basisphenoid form a deep, concave trough that extends back to the basioccipital. The basioccipital is rectangular with parallel-sided margins that slightly overlap the ectotympanic portion of the bulla. On the dorsal surface of the basioccipital is a deep, roughened depression for insertion of the rectus capitis muscle. A hypoglossal foramen is located posterolateral to this depression.

The mastoid process is relatively large and joined to the paroccipital process by a high, thin continuous crest. The paroccipital process is relatively large, pointed, and directed posteroventrally. Medial to the paroccipital-mastoid crest are several large fossae excavated into the lateral part of the exoccipital that are especially well developed in USNM 335432 and are discussed below.

The tympanic bulla is well inflated medially with a smooth, rounded ventral surface. Anterolaterally, the bulla is fused to the postglenoid and mastoid processes (Figure 6). A large transverse groove marks the contact between the anterior margin of the bulla and the postglenoid process. At the anterior end, a large flange of bone separates the eustachian tube from the median lacerate foramen. The stylomastoid foramen is a large, ventrolaterally directed opening. Anteromedial to the stylomastoid foramen is a small exoccipital fossa excavated into the bulla; above this fossa the surface of the bulla is pierced by numerous small foramina. The tympanohyal is posteromedially oriented relative to the stylomastoid foramen and enclosed in a circular fossa by two processes of the bulla. Two relatively deep, large fossa are excavated into the exoccipital medially and posteromedially relative to the tympanohyal; another fossa is located farther posteromedially. At the posterior end of the bulla lies the large elliptical posterior lacerate foramen in a separate but closely associated opening for the posterior carotid foramen. A small process projects into the posterior lacerate foramen from the wall of the posterior carotid canal.

The ventral wall of the bulla was removed on the right side to permit description of the middle ear (Figure 6). Along the medial wall of the bulla is a ledge formed by the carotid canal. This ledge abuts and slightly overlaps the ventral surface of the promontory. The foramen rotundum opens posteriorly and the smaller foramen ovale is positioned dorsolaterally to the foramen rotundum. A shallow broad groove, presumably for the tensor tympani, passes lateral to the promontory and anterior to the foramen ovale. Positioned posterolaterally to this groove is the deep ovoid epitympanic recess. At its anterior margin is a narrow groove that is partially roofed by the septum canalis musculotubarius.

The malleus of USNM 335432 was recovered in good condition, missing only the distal tip of the manubrium (Figure 7). The head of the malleus is not enlarged and it lacks a deep concavity. The posterior surface of the head provides a broad surface of attachment for the incus.

The crown of $\mathrm{I}^{2}$ in USNM 167648 is heavily worn, obscuring morphology. As judged from its root and the alveoli of the other incisors they were transversely narrow (Table 2). The canines are vertically oriented as is the case in the holotype of 


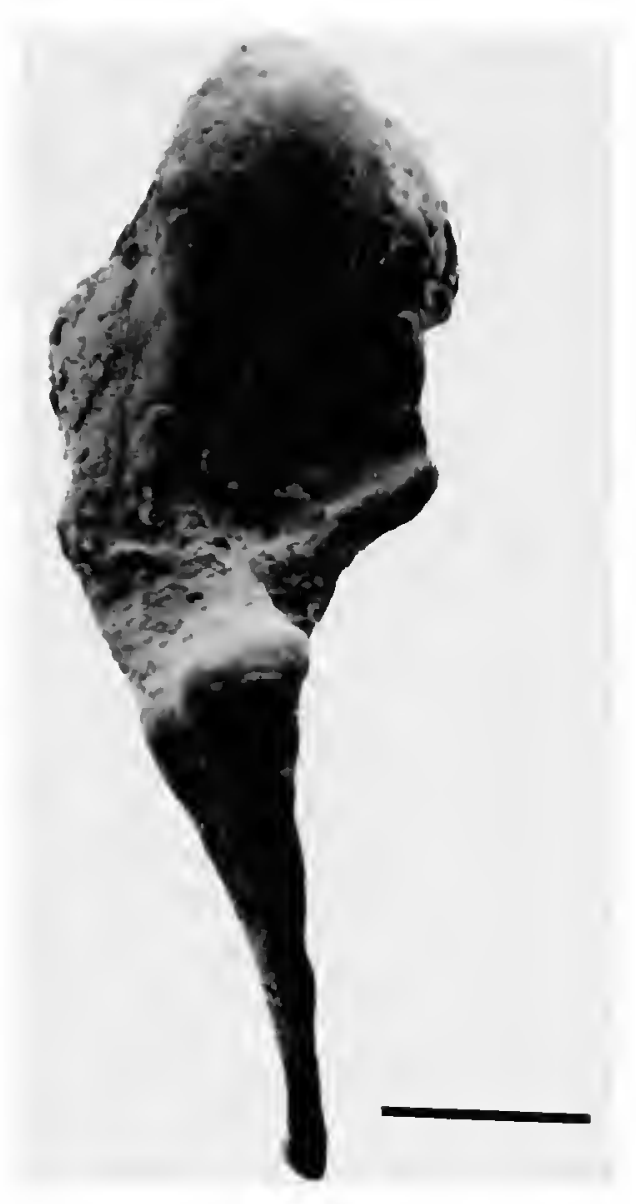

FIGURE 7.-Pteronarctos goedertae USNM 335432, referred male, malleus. $($ Scale $=1 \mathrm{~mm}$.)
Pacificotaria hadromma (Barnes, 1992). Contrary to Bames however, I would argue that this condition does not differ markedly from that in Pteronarctos goedertae. The cheek teeth are positioned close to one another in the tooth row, as is characteristic of the genus.

USNM 335432 preserves the posterior portion of the left $\mathrm{P}^{2}$ and complete left $\mathrm{P}^{3}$ and $\mathrm{P}^{4}$ (Figures 1-4). The posterior portion of $P^{2}$ presents a strong labial cingulum extending from the posterolabial corner of the metacone to the base of the medial cingular ridge that formed the lingual tooth margin.

$\mathrm{P}^{3}$ has a round anterior root and a larger bilobed posterior root (Figures 1,3). The tooth has a quadrilateral occlusal outline with a transversely expanded posterior margin. Strong labial and lingual cingula are developed. The paracone is large and anteriorly positioned. It slopes posteriorly and terminates in a small metacone positioned between the paracone and cingular tooth heel. The protocone is positioned posteromedially relative to the paracone on a cingular ridge. Wear facets on the occlusal surface of the protocone shelf give the appearance of separate cuspules.

$\mathrm{P}^{4}$ is double rooted and triangular in outline. The anterior root is circular in cross-section and the protocone root is fused to the posterolateral root. The large paracone is worn nearly to the level of its base. The smaller metacone, also well worn, is deflected posterolabially and contributes to the wing-like appearance of this tooth. The protocone is relatively large, shelf-like, and centrally positioned. A large crescentic wear facet marks the occlusal surface of this cusp.

As judged from the alveolus, $\mathrm{M}^{1}$ is double rooted with strongly bilobed posterior roots. The anterior root is round in cross-section. Lateral to this root is the posterior root, which consists of a tiny root fused to a large posterolateral root.

TABle 2.-Measurements (mm) of the upper dentition of Pteronarctos goedertae from coastal Oregon. (e = estimated).

\begin{tabular}{|c|c|c|c|c|c|}
\hline & & $\begin{array}{c}\text { Adult male } \\
\text { USNM } 167648\end{array}$ & $\begin{array}{l}\text { Subadult female } \\
\text { USNM } 250320\end{array}$ & $\begin{array}{c}\text { Adult male } \\
\text { USNM } 335432\end{array}$ & $\begin{array}{l}\text { Adult female } \\
\text { USNM } 206274\end{array}$ \\
\hline $\mathrm{I}^{1}$ & $\begin{array}{l}\text { length } \\
\text { width }\end{array}$ & & $\begin{array}{l}3.70 \\
2.70\end{array}$ & & \\
\hline$I^{2}$ & $\begin{array}{l}\text { length } \\
\text { width }\end{array}$ & $\begin{array}{l}5.53 \\
3.63\end{array}$ & $\begin{array}{l}4.27 \\
2.98\end{array}$ & & \\
\hline $\mathrm{I}^{3}$ & $\begin{array}{l}\text { length } \\
\text { width }\end{array}$ & & $\begin{array}{l}4.95^{e} \\
3.86^{e}\end{array}$ & & \\
\hline C & $\begin{array}{l}\text { length } \\
\text { width }\end{array}$ & $\begin{array}{r}11.99 \\
9.73\end{array}$ & $\begin{array}{l}7.64 \\
5.41\end{array}$ & & \\
\hline $\mathbf{P}^{\prime}$ & $\begin{array}{l}\text { length } \\
\text { width }\end{array}$ & & $\begin{array}{l}6.46 \\
4.79\end{array}$ & & \\
\hline $\mathbf{P}^{2}$ & $\begin{array}{l}\text { length } \\
\text { width }\end{array}$ & & $\begin{array}{l}8.44 \\
4.49\end{array}$ & & \\
\hline $\mathbf{P}^{3}$ & $\begin{array}{l}\text { length } \\
\text { width }\end{array}$ & $\begin{array}{l}8.99 \\
5.67\end{array}$ & $\begin{array}{l}8.12 \\
5.05\end{array}$ & $\begin{array}{l}9.67 \\
6.60\end{array}$ & $\begin{array}{l}8.89 \\
6.04\end{array}$ \\
\hline$P^{4}$ & $\begin{array}{l}\text { length } \\
\text { width }\end{array}$ & & $\begin{array}{l}7.69 \\
6.58\end{array}$ & $\begin{array}{l}9.85 \\
8.12\end{array}$ & \\
\hline
\end{tabular}


$\mathrm{M}^{2}$ is represented by a single large bilobed root.

Associated with the skull of USNM 335432 are both mandibular rami that preserve the right canine and the left posterior portion of $P_{2}$ (Figures 8, 9). A right mandibular ramus with $C, P_{2}, P_{4}$, and $M_{1}$ is associated with USNM 167648 (Figure 15). The rami are relatively long and shallow (Table 3 ). Three mental foramina are preserved. The largest one is positioned on the midline of the ramus below the anterior root of $P_{2}$, the next largest is below the posterior root of $P_{3}$. A third smaller foramen, not present in USNM 167648, is located between the anterior and posterior root of $P_{3}$. The symphyseal region is thickened with a gently rounded ventral border. The coronoid process is anteroposteriorly elongate at the base with relatively high, quadrangular apex. The pterygoid process is a short, broad ventromedially projecting shelf.

The canine in USNM 167648 differs from USNM 335432 in being smaller proportionally (Table 3 ). The cheek teeth are closely appressed, postioned directly behind one another in the tooth row. $P_{2}$ through $M_{1}$ are double rooted and $M_{2}$ was single rooted. $P_{2}$ possesses a cingulum completely encircling the tooth. This cingulum in USNM 167648 is less well developed than in USNM 335432. $P_{4}$ and $M_{1}$ are well wom (Figure 15). On $\mathrm{P}_{4}$ a large vertical wear facet extends from the apex of the protoconid to the tooth heel, obliterating any trace of the metaconid. As in $\mathrm{P}_{2}$ a continuous cingulum is prominent. The lower carnassial displays a large protoconid and smaller metaconid positioned posterolingually to it near the base of the crown. The tips of both cusps as well as that of the paraconid are worn. The talonid consists of a worn, crest-like hypoconid.

Axial and appendicular skeletal elements associated with the skull of USNM 335432 include the atlas, the axis, three thoracic vertebrae, a lumbar vertebra, the right scapula, and the right proximal humerus (Figure 10). These are the only known postcranial remains of this taxon. The atlas is similar in size and proportion to that in Enaliarctos mealsi (Berta and Ray, 1990:144). An alar notch is prominently developed. This element differs from Recent otariids in having a shorter, broader transverse process and a flatter dorsal surface of the vertebral arch. The axis differs from that of otariids in having a smaller vertebral foramen; in this feature resembling Thalassoleon mexicanus Repenning and Tedford, 1977:64, pl. 23. Although the posterior portion of the neural spine is broken off in this specimen it would have extended farther posteriorly than in Recent otariids. Two of the three thoracic vertebrae are anterior elements as judged by their long spinous processes. A more posterior position for the third thoracic vertebra is suggested by its shorter spinous process that is more posteriorly inclined and presence of a deeper centrum. The lumbar vertebra represented (L4 or L5) is distinguished by its very short, broad neural spine and long, slender transverse processes.

The proximal end of the humerus is similar to that in Enaliarctos in having an enlarged greater tuberosity that is not elevated above the head. The development of a strong deltopectoral crest with an overhanging margin in Pteronarctos is clearly displayed (Figure 10). A deep fossae is present on the shaft lateral to the deltopectoral crest.

The lack of a completely ossified vertebral border on the scapula suggests that this individual was a young adult. The scapula resembles that of Enaliarctos and Thalassoleon in presenting one long continuous cranial and vertebral border. This element is better preserved than in Enaliarctos mealsi and establishes that a postscapular fossa was not present in Pteronarctos. Although several ridges are present on the lateral surface, a distinct anterior scapular ridge dividing the supraspinous fossa, as is diagnostic of otariids, is not developed. The coracoid process is large and hook-like.

Adult Female: In addition to the holotype skull of Pteronarctos goedertae described by Bames (1989) a skull from the Emlong collection is identified as female. USNM 206274 is missing the anterior rostrum and posterior portion of both zygomatic arches (Figures 16, 17). The dorsal surface of the entire skull is weathered away. All sutures are fused except the maxillary-palatine suture indicating that this specimen is an older individual than others referred to this taxon. In morphology and size the skull closely resembles the type and referred skull of $P$. goedertae (including $P$. piersoni) described by Barnes $(1989,1990)$. Similarities and differences between the USNM specimen and the LACM specimens referred to this taxon are noted below.

The skull is low with a conspicuously elongate, narrow interorbital region and large orbits. The nasolabialis fossae are relatively shallow although more pronounced than in LACM 123083.

A distinct supraorbital process is developed at the anterior end of the interorbital region. Although the braincase is

TABLE 3.-Measurements (mm) of the mandible and lower dentition of Pteronarctos goedertae from coastal Oregon (e = estimated).

\begin{tabular}{|c|c|c|}
\hline & $\begin{array}{c}\text { Adult male } \\
\text { USNM } 167648\end{array}$ & $\begin{array}{c}\text { Adult male } \\
\text { USNM } 335432 \\
\end{array}$ \\
\hline Length of ramus & $162.74^{e}$ & 173.17 \\
\hline Length of tooth row $\mathrm{C}-\mathrm{M}_{2}$ & 71.84 & 73.25 \\
\hline Depth of ramus below $P_{3}$ & 27.06 & 26.06 \\
\hline $\begin{array}{l}\text { length } \\
\text { width }\end{array}$ & $\begin{array}{r}10.75 \\
7.83\end{array}$ & $\begin{array}{r}13.17 \\
8.86\end{array}$ \\
\hline$P_{1} \begin{array}{l}\text { length } \\
\text { width }\end{array}$ & & \\
\hline $\mathrm{P}_{2} \begin{array}{l}\text { length } \\
\text { width }\end{array}$ & $\begin{array}{l}8.31 \\
4.75\end{array}$ & \\
\hline$P_{3} \begin{array}{l}\text { length } \\
\text { width }\end{array}$ & & \\
\hline $\mathbf{P}_{4} \begin{array}{l}\text { length } \\
\text { width }\end{array}$ & $\begin{array}{l}9.34 \\
4.60\end{array}$ & \\
\hline$M_{1} \begin{array}{l}\text { length } \\
\text { width }\end{array}$ & $\begin{array}{r}11.09 \\
4.68\end{array}$ & \\
\hline
\end{tabular}



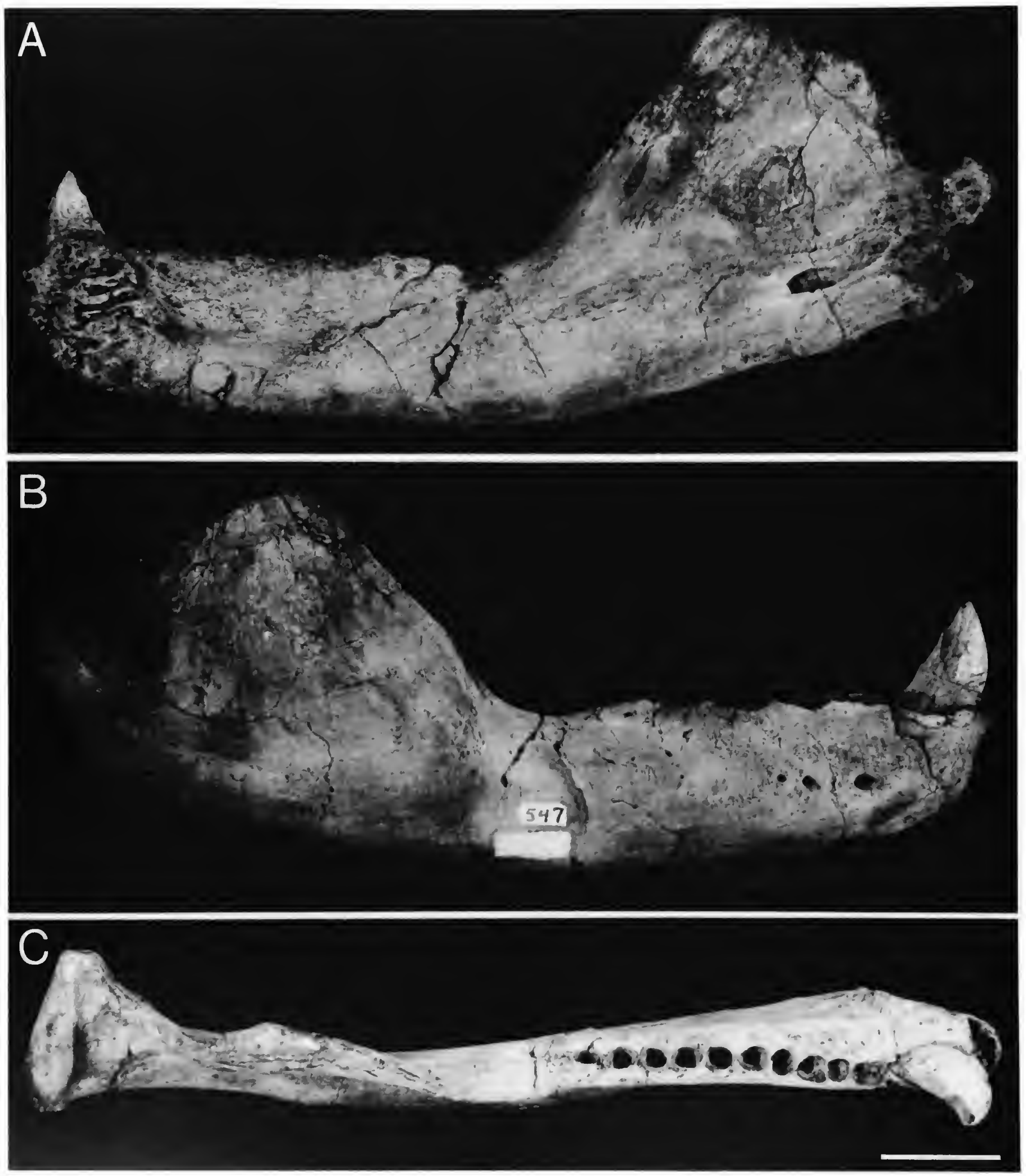

FIGURE 8.-Pteronarctos goedertae USNM 335432, referred male, associated right lower jaw: A, lateral view; B, medial view; $C$ occlusal view. $($ Scale $=2 \mathrm{~cm}$.) 

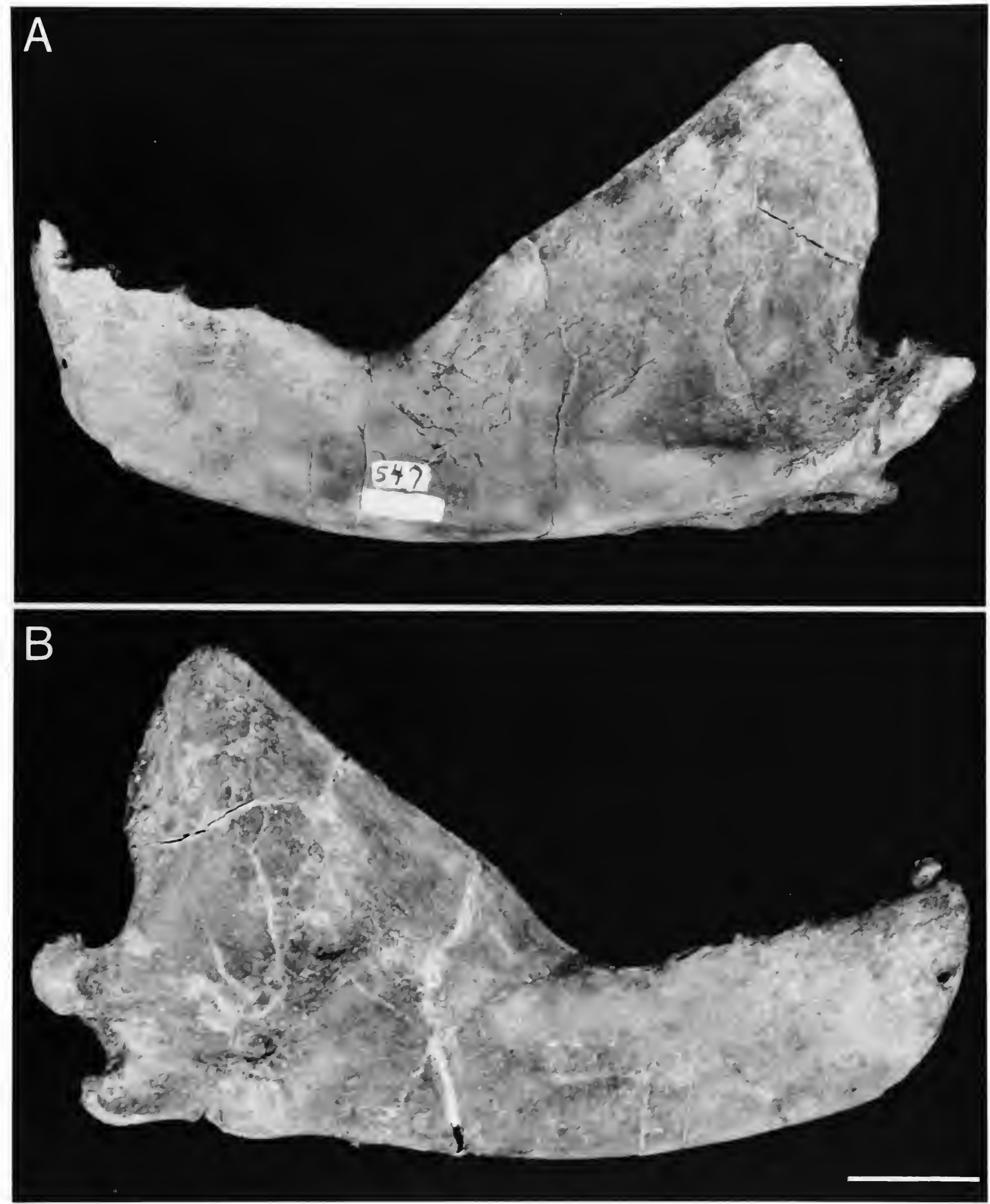

FIGURE 9.-Pteronarctos goedertae, USNM 335432, referred male, associated left lower jaw: A, lateral view; в, medial view. (Scale $=2 \mathrm{~cm}$.) 

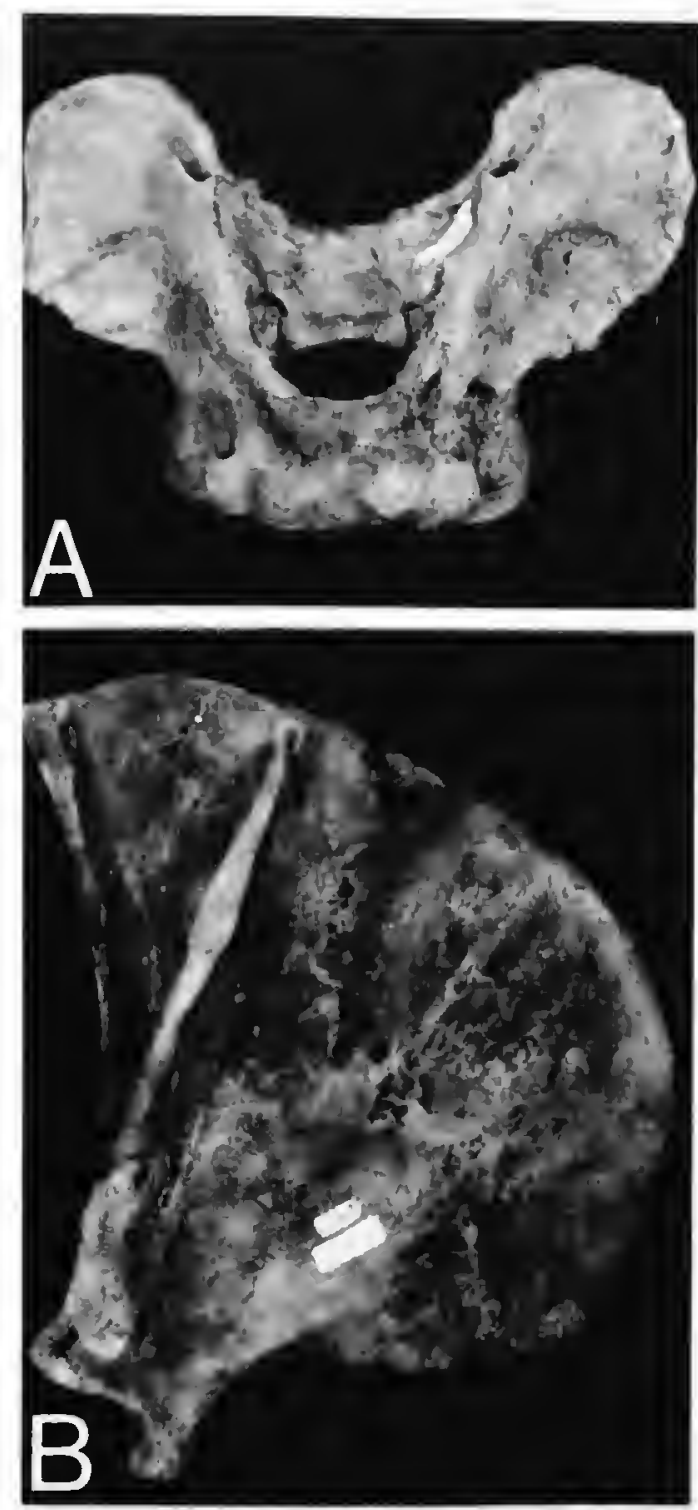

FIGURE 10.-Pteronarctos goedertae, USNM 335432, referred male, associated skeletal elements: $A$, dorsal view of atlas; $B$, lateral view of right scapula; C, D, E, anterior, lateral, and medial views of right proximal humerus. (Not to scale.)
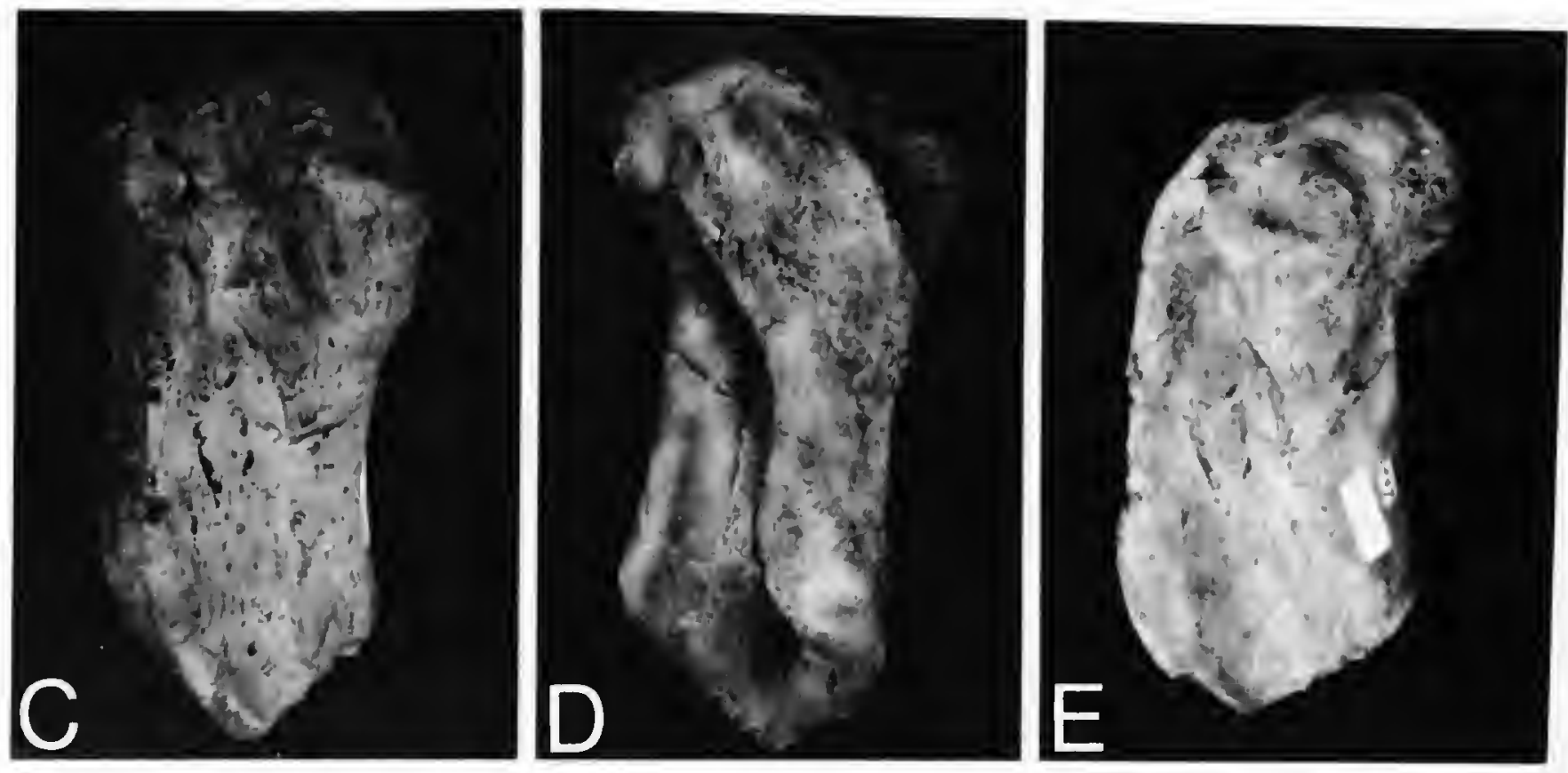

distorted owing to compression, a fossa corresponding to the pseudosylvian sulcus is present on the lateral side of the braincase; it is similar in degree of development to LACM specimens. The occipital shield represented only by the condyles encloses a large foramen magnum.

Much of the medial wall of the orbit is broken away. The zygomatic arch at its juncture with the maxilla differs from the LACM specimens in lacking a fossa although the shelf slopes anteroposteriorly as is in the former specimens (Figure 17). The infraorbital foramen are transversely compressed as in LACM 123083.

The USNM specimen possesses a moderately arched palate, achieving maximum depth adjacent to $\mathrm{P}^{4}$ at the midpoint of the palate; in the LACM specimens the palate is flat or slightly arched as noted by Barnes $(1989,1990)$. The maxillary-palatine suture is distinct. The anterior palatine foramen is located adjacent to the midline of the palate and extends from the posterior root of $\mathrm{P}^{4}$ to the posterior root of $\mathrm{P}^{2}$. 

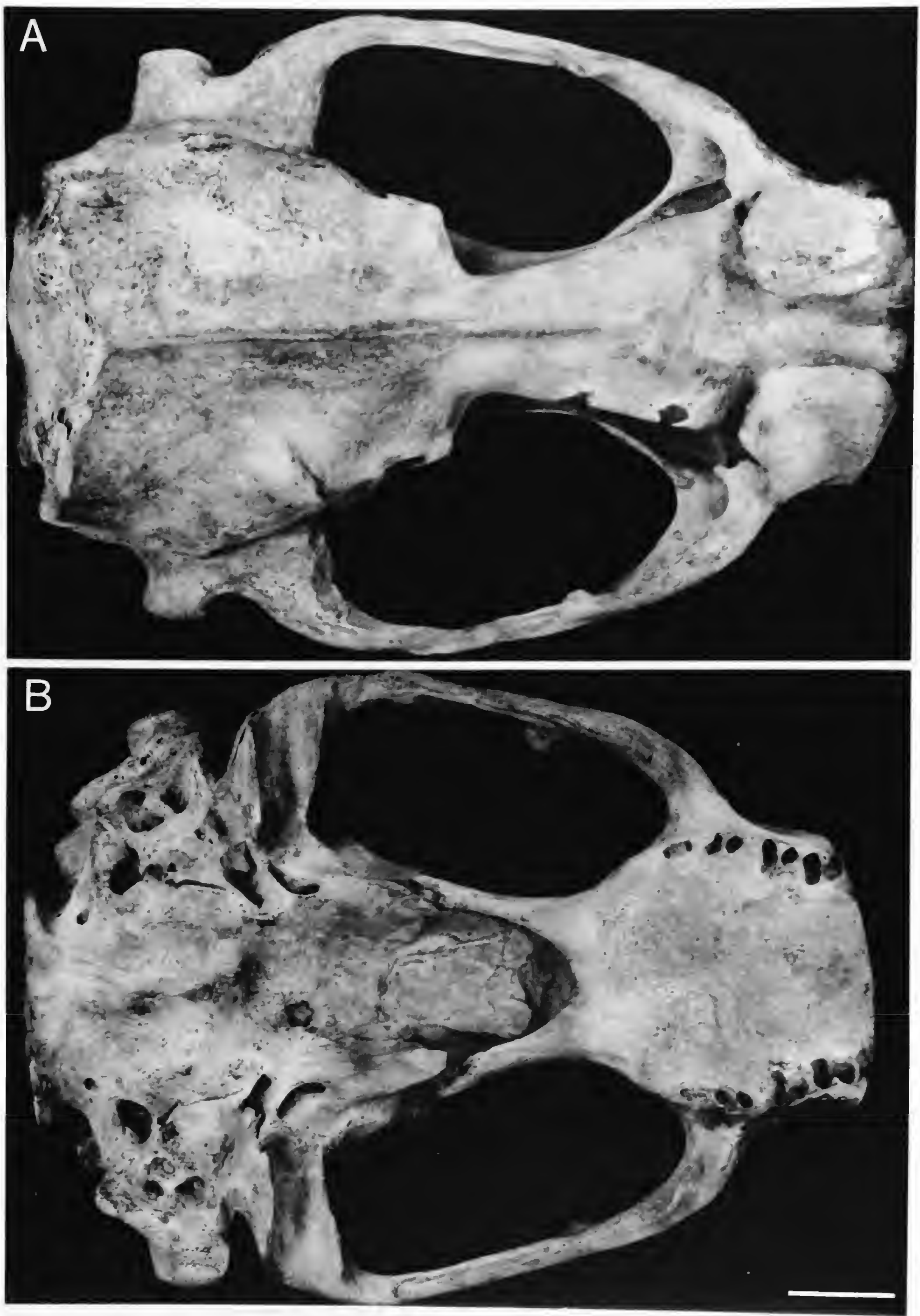

FIGURE 11.-Pteronarctos goedertae, USNM 250282, referred male, skull: A, dorsal view; B, ventral view. $($ Scale $=2 \mathrm{~cm}$. $)$ 


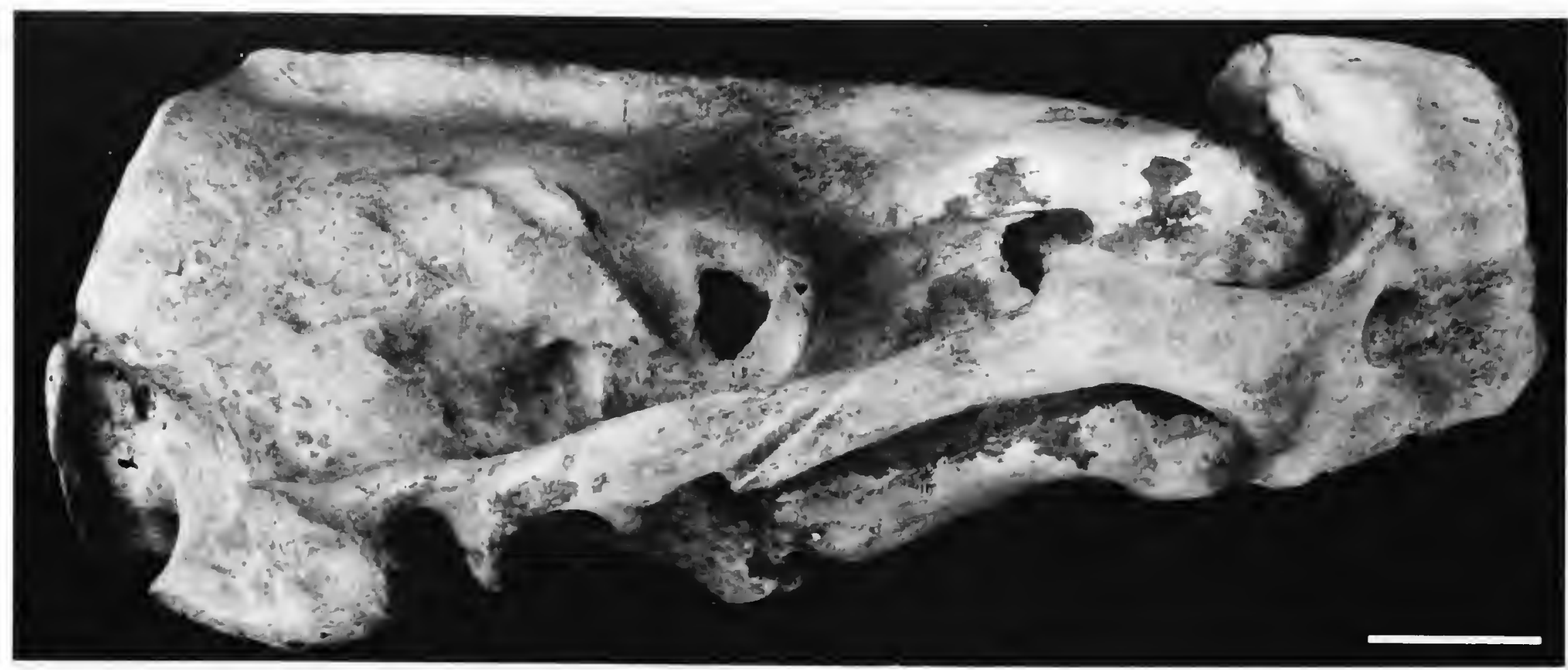

FIGURE 12.-Pteronarctos goedertae, USNM 250282, referred male, skull, lateral view. (Scale $=2 \mathrm{~cm}$.)

The pterygoid-palatine strut is inflated and resembles closely that of other specimens referred to this taxon. A deep fossa is excavated into the basioccipital for insertion of the rectus capitus muscle.

The large, pointed paroccipital process is oriented posteriorly and connected to the large mastoid by a continuous, relatively thin shelf-like crest of bone.

The tympanic bulla in USNM 250282 closely resembles those of LACM 127972; its medial portion is inflated. The holotype of $P$. goedertae, LACM 123083, differs in having the bullae oriented more anteriorly on the basicranium, such that the anterior end of the tympanic bulla extends anteromedial to the postglenoid process. The preglenoid process, especially the lateral portion is more prominent in the USNM specimen than in either LACM specimens. The postglenoid foramen is visible in a groove between the bulla and the postglenoid process. The ventromedially directed stylomastoid foramen is separated from the fossa for the tympanohyal by a narrow bridge of bone. Several small foramina pierce the bullae medial to the stylomastoid foramen. A shallow fossa is excavated into the exoccipital posterior to the tympanohyal fossa.

The ventral wall of the bulla was removed on the right side. The morphology of the middle ear is very similar to that described for USNM 335432.

USNM 206274 preserves a single tooth, a right $\mathrm{P}^{3}$ with a distinctly bilobed posterior root. This tooth differs from USNM 335432 in having a larger metacone, separated from the paracone by a well defined notch (Figure 16). As judged from the root pattern of the alveoli the teeth were closely spaced in the toothrow. The posterior root of $\mathrm{P}^{4}$ and $\mathrm{M}^{1}$ and the posterior root of $\mathrm{M}^{1}$ are weakly bilobed. The $\mathrm{M}^{2}$ alveolus indicates that this tooth was large and bilobed.
Subadult Females: As judged from their small size and proportion, weakly developed sagittal crest, unworn cheekteeth, and degree of suture closure two female subadult individuals are represented in the Emlong collection. USNM 250320 (E-47) is a nearly complete skull with right $\mathrm{I}^{1-2}, \mathrm{C}$, $\mathrm{P}^{3-4}$, and left $\mathrm{I}^{2-3}, \mathrm{C}, \mathrm{P}^{1-4}$ (Figures 18-20). USNM 250323 is a mediolaterally compressed skull with $\mathrm{P}^{4}$ and right $\mathrm{I}^{1}$. Both skulls have five out of nine cranial sutures open indicating that they are young individuals (Sivertson, 1954).

The skull is low and flat in lateral profile; the deeper, arched profile of USNM 250323 is the result of extreme mediolateral compression of the skull. The nasolabialis fossa is inconspicuous. The fossa between the roots of $\mathrm{I}^{3}$ and the canine is well developed. The nasals, which are well preserved, are long and narrow and not as flared anteriorly as in USNM 335432. The nasal-frontal contact is similar to that in USNM 335432 with the nasals presenting a gently curved rather than straight posterior margin. On the left side a small sliver of the frontal separates the maxilla and nasal.

The sagittal crest is slightly elevated anteriorly, flattening as it extends posteriorly. USNM 250323 is the only Emlong Pteronarctos goedertae specimen with an intact orbital region that is solid bone in construction. The small, rounded supraorbital processes in USNM 250320 are positioned at the middle of the interorbital constriction, differing from their anterior position in USNM 206274 and USNM 335432; this difference may reflect ontogenetic variation. A deep pseudosylvian sulcus is excavated into the lateral wall of the braincase.

The zygomatic arch joins the maxilla at a low, horizontal juncture as in USNM 206274; differing in having a strongly developed fossa present on the ventral surface of the zygoma. 

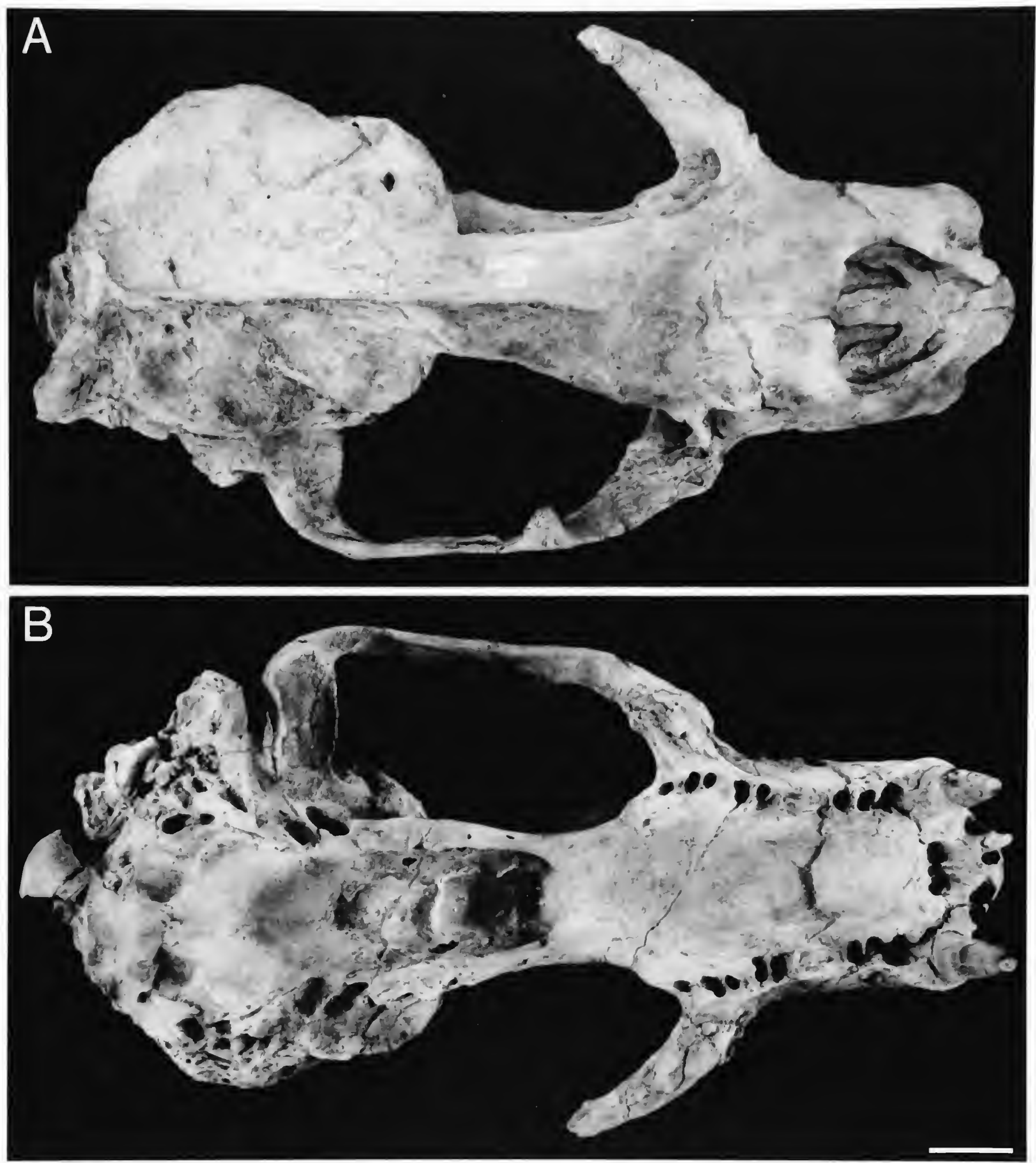

FIGURE 13.-Pteronarctos goedertae, USNM 167648, referred male, skull: A, dorsal view; B, ventral view. (Scale $=2 \mathrm{~cm}$.) 


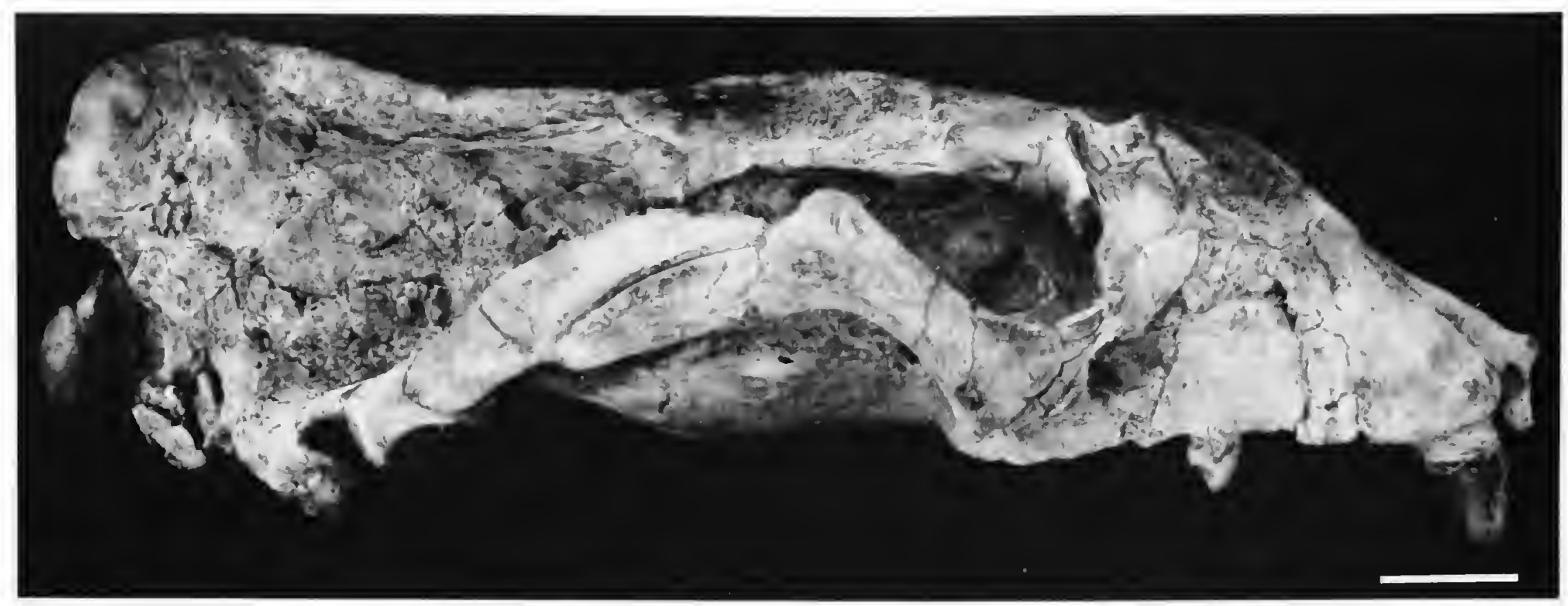

FIGURE 14.-Pteronarctos goedertae, USNM 167648, referred male, skull, lateral view. (Scale $=2 \mathrm{~cm}$.)

The infraorbital foramen in USNM 250323 is circular and elliptical in USNM 250320.

The palate is moderately arched as in USNM 206274. The anterior palatine sutures extend from the posterior root of $\mathrm{P}^{3}$ to the anterior root of $\mathbf{P}^{2}$.

The mastoid and paroccipital processes are connected by a relatively high continuous crest.

The auditory region of USNM 250320 is especially well preserved and the ventral wall of the left bulla was removed. The morphology of the middle ear in comparison with that of other members of this taxon presents no major differences. There is conspicuous inflation of the caudal entotympanic and medial portion of the bulla. The malleus and incus were both recovered in excellent condition (Figure 20). The malleus closely resembles that of USNM 354352. The incus bears a deep concavity for articulation with the malleus.

$\mathrm{I}^{1-2}$ preserved in USNM 250320 display a transverse groove that extends across the crown. $\mathrm{I}^{3}$ is larger in size than $\mathrm{I}^{1-2}$ with a nearly circular cross section in the holotype and referred specimens. $\mathrm{P}^{3}$ broadens posterolingually and possesses a distinct bilobed posterior root.

$\mathrm{P}^{4}$ is double rooted with a single anterior root and fused posterior roots. The tooth consists of a single large centrally positioned paracone and small metacone separated by a well defined notch. The small protocone is centrally positioned relative to the paracone. The alveoli of $M^{1}$ differs from the former tooth in having the bilobed protocone root positioned farther posteriorly. As judged from the alveoli, $\mathrm{M}^{2}$ was relatively large and double rooted.

\section{Status of Pacificotaria and Pteronarctos piersoni}

Bames (1992) lists 20 characters distinguishing Pacificotaria from its closest relative Pteronarctos. Of these, 11 are of questionable significance owing to either individual variation, sexual variation, or problematic character observation. Three additional characters obtain at a more general level; the remaining six characters are potentially diagnostic.

Among those characters suspected to represent individual variation are (character numbering scheme is based on the order listed by Barnes, 1992:3): (8) palatine grooves shorter and less prominent; (10) transverse prominence between the supraorbital processes rather than oblique crests; (12) zygomatic arch thicker and deeper dorsoventrally; (16) region of basicranium between glenoid fossa and internal naris more convex; and (19) dorsal surface of cranium much more convoluted and rugose. Both states of character $10-a$ transverse prominence and oblique crests between the supraorbital process-can be observed on USNM 167648. For character 8, USNM 335432 displays deep palatine grooves that extend from $\mathrm{P}^{4}$ to $\mathrm{P}^{2}$, as far anteriorly as in any specimen referred to Pteronarctos (Barnes, $1989,1990)$. One character probably represents sexual variation: (20) sagittal and nuchal crests larger. Barnes (1990) notes that presence of a sagittal crest is typical of adult male otarines. Several additional characters are poorly defined, for example, character 4: small eminence on narial border of premaxilla near junction with nasal bones. This eminence is also visible in the holotype of Pteronarctos goedertae (LACM 123083) but only on the left side. The same observation is true for USNM 167648. Another problematic feature is character 6: protocone root of $\mathrm{M}^{1}$ more posteriorly positioned relative to metacone. Since the protocone and metacone roots of Pteronarctos are fused it is not possible to discern this feature in this taxon, making it impossible to compare this feature with the condition in Pacificotaria. Barnes (1992:3) also lists as diagnostic of Pacificotaria character 18 mastoid process more curved, relatively larger and extended farther laterally, forming a more sigmoid crest. Observation of this feature in the holotype of Pteronactos piersoni (LACM 127972) reveals a comparable degree of development of the mastoid process thus invalidating 

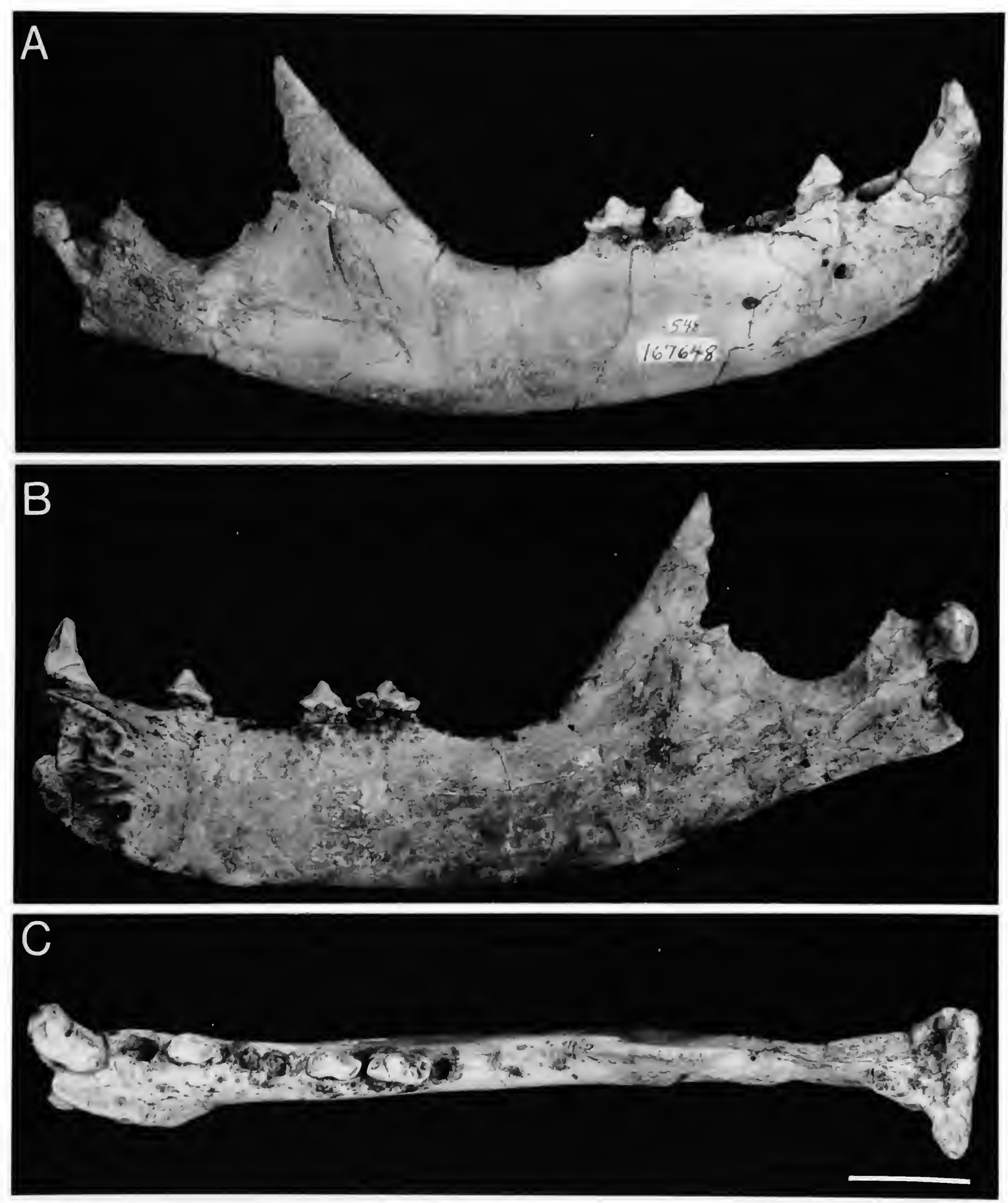

FIGURE 15.-Pteronarctos goedertae, USNM 167648, referred male, associated right lower jaw: A, lateral view; B, medial view; C, occlusal view. (Scale $=2 \mathrm{~cm}$.) 

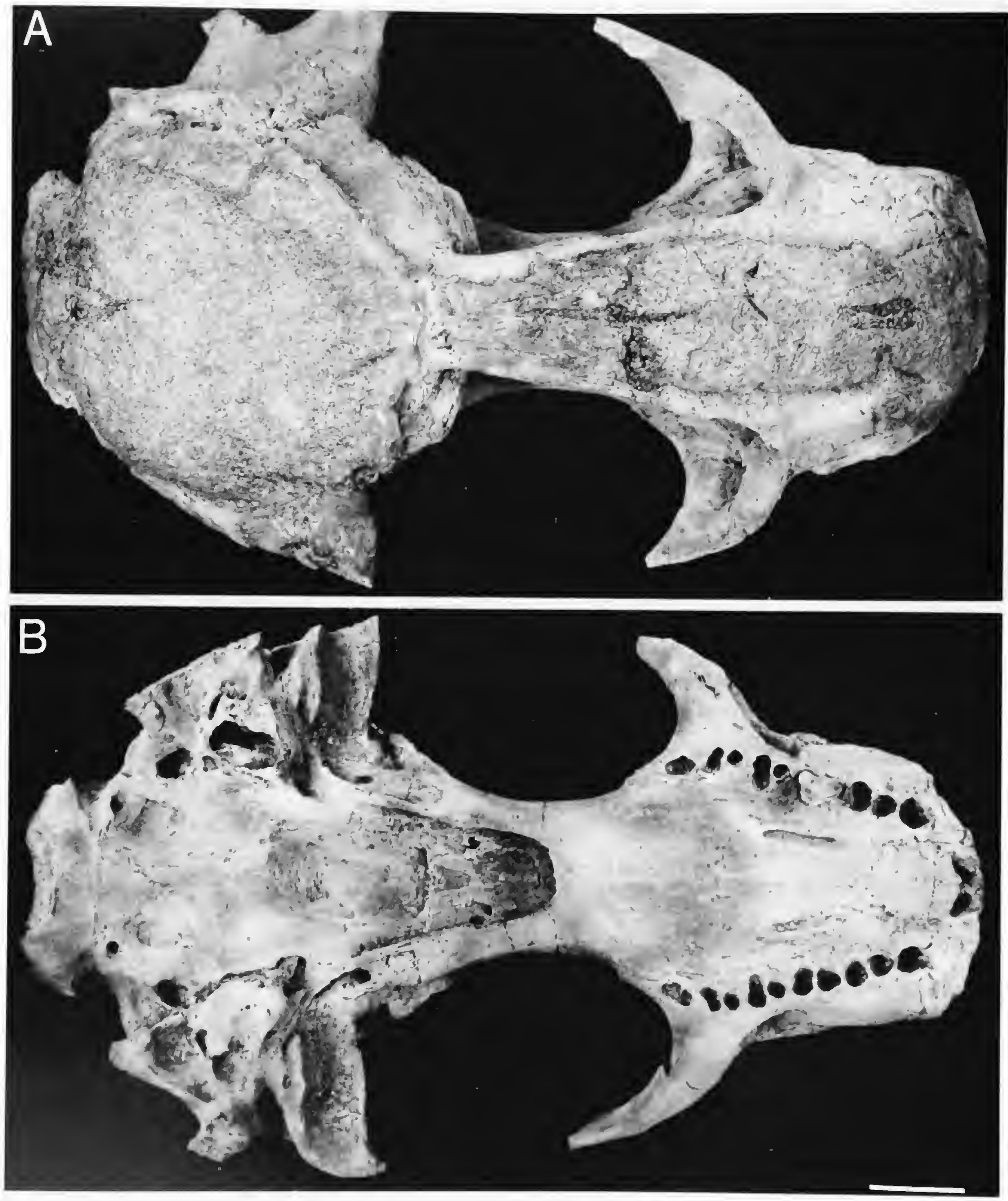

FigURE 16.-Pteronarctos goedertae, USNM 206274, referred female, skull: A, dorsal view; B, ventral view. (Scale $=2 \mathrm{~cm}$.) 


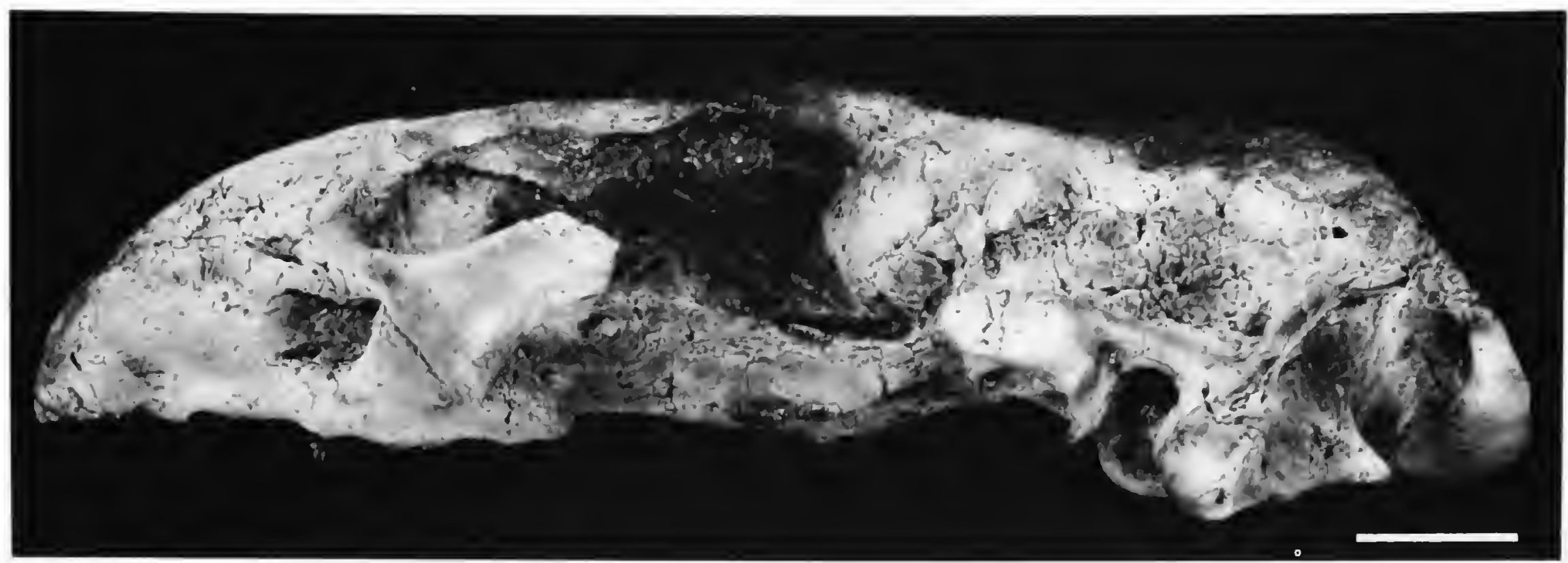

FIGURE 17.-Pteronarctos goedertae, USNM 206274, referred female, skull, lateral view. (Scale $=2 \mathrm{~cm}$.)

this observation. With regard to character 9-dorsal surface of rostrum more nearly horizontal-this feature does not distinguish Pacificotaria from the holotype of Pteronarctos piersoni, LACM 127972. Another diagnostic feature of Pacificotaria according to Bames (1992) is character 14: cheek tooth row straighter. This feature is not obvious from visual inspection or measurement of specimens referred to either Pacificotaria or Pteronarctos. One might expect that this difference would be reflected in palatal width at $\mathrm{P}^{4}$. When comparisons are made of palate width (measured at $\mathrm{P}^{4}$ ) to palate length among Pteronarctos species and Pacificotaria the ratio of palate width to length is $52.5 \%$ for Pacificotaria compared to $53.9 \%$ and 52.5\% for Pteronarctos piersoni and Pteronarctos goedertae, respectively. Such small differences between these specimens is not considered significant.

Characters that are identified as symplesiomorphies include: (3) proximal fossa on anterior surface of rostrum along premaxillary-maxillary suture; (15) anteroventrally directed preglenoid process at lateral portion of glenoid fossa; and (17) pharyngeal tubercle of basioccipital larger and more convex. None of these features is unique to Pacificotaria. Although none are present in Pteronarctos all can be observed in specimens referred to Enaliarctos. Since these characters occur in Enaliarctos they represent retension of primitive characters and thus cannot be used as derived features to diagnose Pacificotaria as proposed by Barnes (1992). Character 3 is present in the holotype of Enaliarctos barnesi (USNM 314295). The holotype of Enaliarctos mealsi (LACM 1627) displays an anteroventrally directed preglenoid process (character 15). A specimen referred to Enaliarctos mitchelli (USNM $175637)$ and the holotype of $E$. mealsi cited above both display prominent pharyngeal tubercles of the basioccipital (character 17).

The remaining six characters potentially diagnostic of Pacificotaria include: (1) cranium with wider rostrum at canines; (2) anterior narial opening larger with wider and flatter ventral floor; (5) larger $\mathrm{I}^{3}$; (7) nasolabialis fossa deeper and inclined more vertically; (11) orbit directed more anteriorly and laterally forming a cup-like structure and departing from the cheek region more abruptly; and (13) palate more vaulted. Through comparison of Recent pinniped species and study of this relatively large sample of fossil pinnipeds I consider these differences within the range of variation of a single pinniped species. Several of these features, especially characters 1 and 7 are likely the result of sexual dimorphism. In summary, I recommend synonymy of Pacificotaria with Pteronarctos; the purported diagnostic characters of Pacificotaria are within the range of individual and sexual variation for Pteronarctos goedertae.

Barnes (1990) presented a list of 17 cranial and dental characters to distinguish $P$. piersoni from $P$. goedertae. Review of these characters presented below (numbering scheme follows the order of characters listed by Barnes, 1990:2) suggests that specific separation of these taxa is not well founded. Therefore, I consider $P$. piersoni the junior synonym of $P$. goedertae.

In addition, a number of cranial measurements and statistical parameters for adult male Northern fur seals, Callorhinus ursinus (Linnaeus), representing a single population from St. Paul Island in the Bering Sea were conducted for comparison with the fossil samples of Pteronarctos (Table 4).

1. Cranium with rostrum deeper dorsoventrally. Although Barnes provides no measurements to support this claim, absolutely and relatively (compared to skull length) the rostral depth of the skull of Pteronarctos piersoni $(=58.50 \mathrm{~mm})$ is $27 \%$ of skull length $(=214.37$ $\mathrm{mm}$ ) while in Pteronarctos goedertae $(=42.79 \mathrm{~mm})$ this figure is approximately $24 \%$ of skull length (= 206.60 $\mathrm{mm}$ ). Among Recent Callorhinus this dimension ranged 

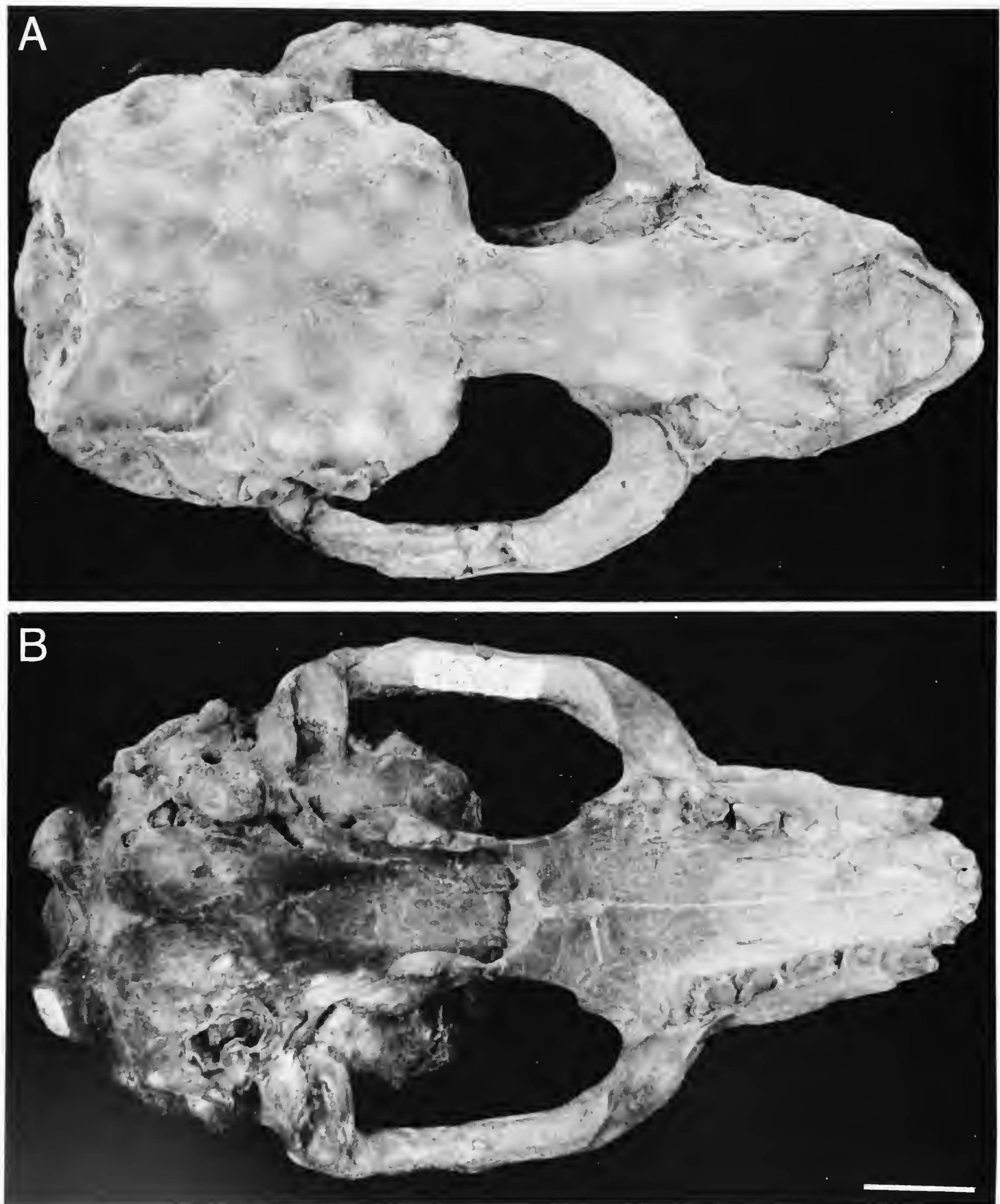

FIGURE 18.-Pteronarctos goedertae, USNM 250320, referred subadult female, skull: A, dorsal view; B, ventral view. (Scale $=2 \mathrm{~cm}$.) 


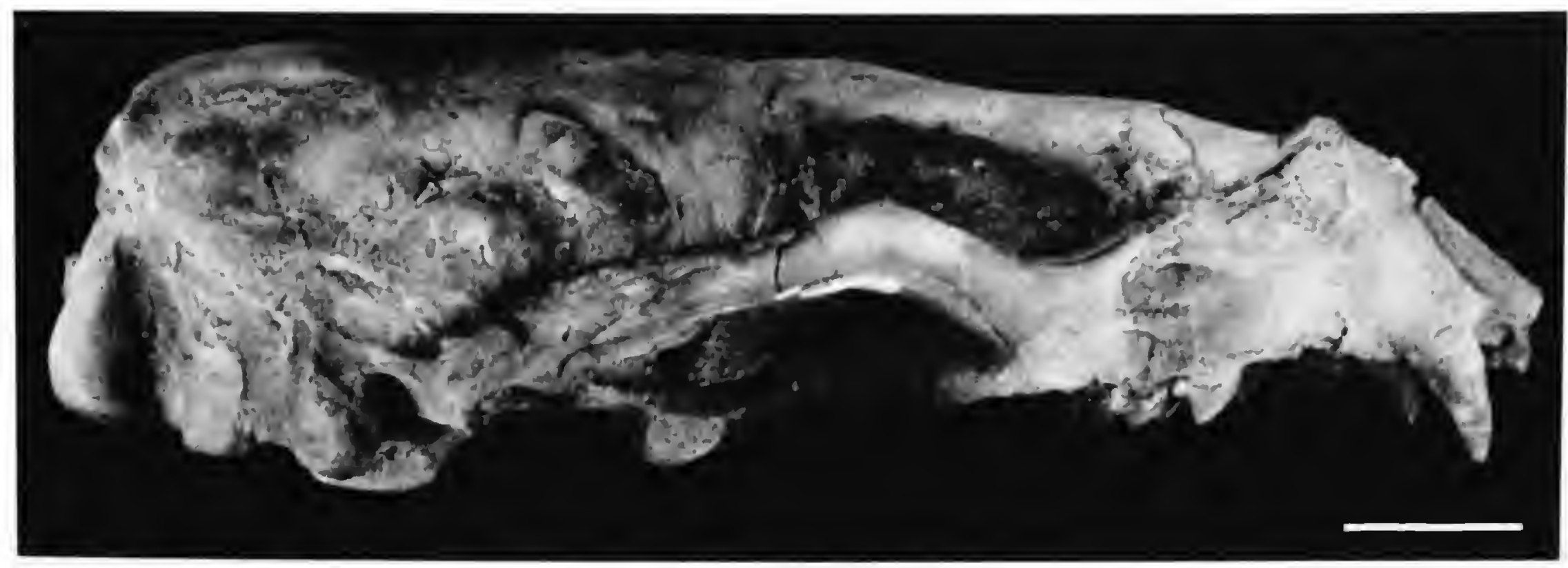

FIGURE 19.-Pteronarctos goedertae, USNM 250320, referred subadult female, skull, lateral view. (Scale $=2$ cm.)
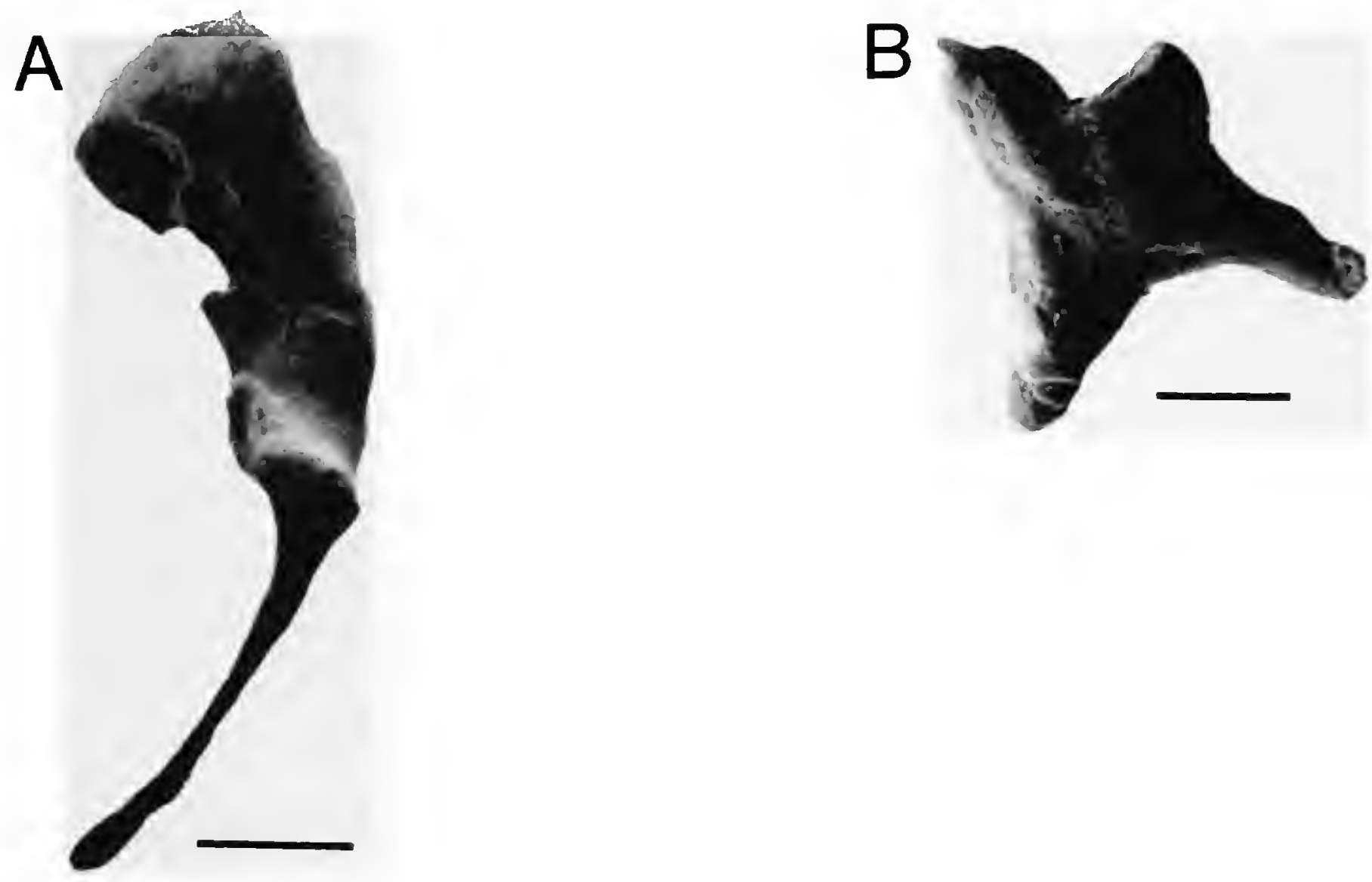

FIGURE 20.-Pteronarctos goedertae USNM 250320, referred subadult female, skull: A, malleus; B, incus. (Scale $=1 \mathrm{~mm}$.)

between $23 \%-28 \%$ of skull length. The coefficient of variation (C.V.) for this sample is 7.2 , which is within the expected range for mammalian populations (Simpson et al., 1960). Thus, this small difference between Pteronarctos species would likely fall within the range of variation of a single species.

2. Nasolabialis fossa deeper and more distinct. A deeper nasolabialis fossa does not appear to characterize the paratype of $P$. piersoni (compare Barnes, 1990, figs.
$4,5)$ thus suggesting individual variation in this feature for this taxon.

3. Anterior ends of nasal bones less deeply emarginate. Given the range of variation in the degree of emargination of the nasal bones in the related species, Enaliarctos mitchelli (holotype, UCMP 100391 and referred specimen, USNM 175637), the significance of this difference is questioned.

4. Dorsal surface of rostrum anteroventrally slop- 
TABLE 4.-Statistical parameters of cranial dimensions from a single population of Recent Callorhinus ursinus adult males from St. Paul Island, Bering Sea, in the National Museum of Natural History ( $N=$ number of specimens; $M=$ mean; S.D. = standard deviation; $V=$ coefficient of variation).

\begin{tabular}{l|lccr}
\hline \multicolumn{1}{c|}{ Character } & N & M & S.D. & V \\
\hline 1. Rostral depth & 25 & 62.66 & 4.51 & 7.20 \\
2. Nasal process premaxilla & 25 & 17.55 & 3.26 & 18.57 \\
$\quad$ length & & & & \\
3. Pterygoid process length & 25 & 17.62 & 2.51 & 14.24 \\
4. Palate length & 25 & 88.47 & 7.36 & 8.32 \\
5. Tympanic bulla & 25 & 32.77 & 3.13 & 9.59 \\
\hline
\end{tabular}

ing. Although the slope of the rostrum differs between $P$. goedertae and $P$. piersoni this difference is encompassed within the range of variation observed in the larger sample of Pteronarctos goedertae studied here.

5. Ascending (nasal process) of premaxilla shorter and transversely broader. A comparision of the length of the nasal processes of the premaxilla relative to skull length between $P$. goedertae $(=23.52 \mathrm{~mm})$ and $P$. piersoni $(=15.22 \mathrm{~mm})$ reveals a difference between the two species, $7 \%$ ( $P$. piersoni) vs. $11 \%$ ( $P$. goedertae). In the Recent sample of Callorhinus, however, this dimension had a high C.V. (= 18.6), which suggests that this measurement may also be highly variable among fossil Pteronarctos (Table 4).

6. Infraorbital foramen of large diameter. Although not specified by Barnes (1990) it is the anteroposterior diameter as opposed to the transverse diameter that is larger in $P$. piersoni than in $P$. goedertae. Since the significance of this character as diagnostic for $P$. piersoni is a possibility, both conditions of the infraorbital foramen (narrow, elliptical vs. round, circular) were noted in the distribution of this character in Pteronarctos goedertae.

7. Zygomatic arch more bowed dorsally. There is only a slight difference in the degree of dorsal curvature of the zygomatic arch of Pteronarctos piersoni in comparison to $P$. goedertae.

8. Pterygoid process of palatine smaller. Although Barnes (1990) provides no measurement of this feature, the length of the pterygoid process of the palatine relative to palatal length is nearly $11 \%(=9.91 / 93.90 \mathrm{~mm})$ in Pteronarctos piersoni and $10 \%$ in $P$. goedertae (= $10.07 / 97.75 \mathrm{~mm}$ ). Such a slight difference is not considered significant considering that among Recent Callorhinus, this dimension is highly variable with a C.V. of 14.2 (Table 4).

9. Palate shorter. Palatal length is $44 \%$ of skull length in $P$. piersoni $(=93.90 / 214.37 \mathrm{~mm})$ and $47 \%$ of skull length in $P$. goedertae $(=97.75 / 206.60 \mathrm{~mm})$, a difference that is not considered significant.

10. Auditory region located farther posteriorly on the basicranium. This is another feature, which initially distinguished $P$. piersoni from $P$. goedertae, but examination of additional material of Pteronarctos indicates that this character is found associated with specimens that otherwise possess $P$. goedertae features (eg., USNM 206274).

11. Tympanic bulla smaller. Measurement data does not support this claim. Bullar length and width relative to skull length for $P$. piersoni are $10 \%$ and $9 \%$ (= $21.24 / 20.17 \mathrm{~mm}$ ) respectively. Both of these dimensions are $10 \%(21.56 / 20.86 \mathrm{~mm})$ for $P$. goedertae.

12. Mastoid process relatively thicker anteroposteriorly. This is a highly variable character among related pinnipedimorphs (eg., Enaliarctos) and the recent sample of Callorhinus.

13. Crest between mastoid process and paroccipital process thicker. As was the case for the previous character, this feature is subject to considerable variation in related fossil and recent species.

14. Occipital condyles projecting farther and more prominently from occipital shield. As was true for previous characters the availability of a larger sample of Pteronarctos indicates that this feature is not exclusively found in specimens referred to $P$. piersoni.

15. Canine crown more vertically oriented. The difference in orientation of the canine was measured as the angle of the canine (at the apex of the crown) relative to the horizontal plane of the palate, this angle measures $20^{\circ}$ in $P$. piersoni and $23^{\circ}$ in $P$. goedertae, too slight a difference to be considered significant.

16. Cheek tooth rows more laterally bowed. Although Barnes (1990) notes that the cheek tooth row of $P$. piersoni is more bowed laterally between $\mathrm{P}^{4}$ and $\mathrm{M}^{1}$ measurements of palatal width relative to palatal length do not show a significant difference between $P$. goedertae and $P$. piersoni; palatal width is $54 \%$ of palatal length in $P$. piersoni $(54.13 / 99.66 \mathrm{~mm})$ compared to $55 \%$ for $P$. goedertae $(54.44 / 104.16 \mathrm{~mm})$.

17. Posterior root of $M^{I}$ distinctly bilobed. A larger sample of Pteronarctos reveals that this feature is not found exclusively in specimens referred to $P$. piersoni.

\section{Higher-level Relationships of Pteronarctos}

According to Barnes (1992) Pteronarctos and Pacificotaria together with Enaliarctos and Pinnarctidion are recognized as "enaliarctine" pinnipeds. In his cladogram (Barnes, 1992, fig. 10), Pacificotaria, Pteronarctos, and Pinnarctidion are more closely related to each other than either is to Enaliarctos. He listed the following characters to support this arrangement: $\mathrm{P}^{4}$ reduced and located posteriorly; $\mathrm{P}^{3}$ with protocone and bilobed posterior root; postorbital process tabular and bent medially; and all cheek teeth reduced in size. I have recognized the derived condition of $\mathrm{P}^{4}$ at a different level of generality, one uniting Pteronarctos and all other pinnipeds exclusive of Enaliarctos. The condition of the postorbital process in 


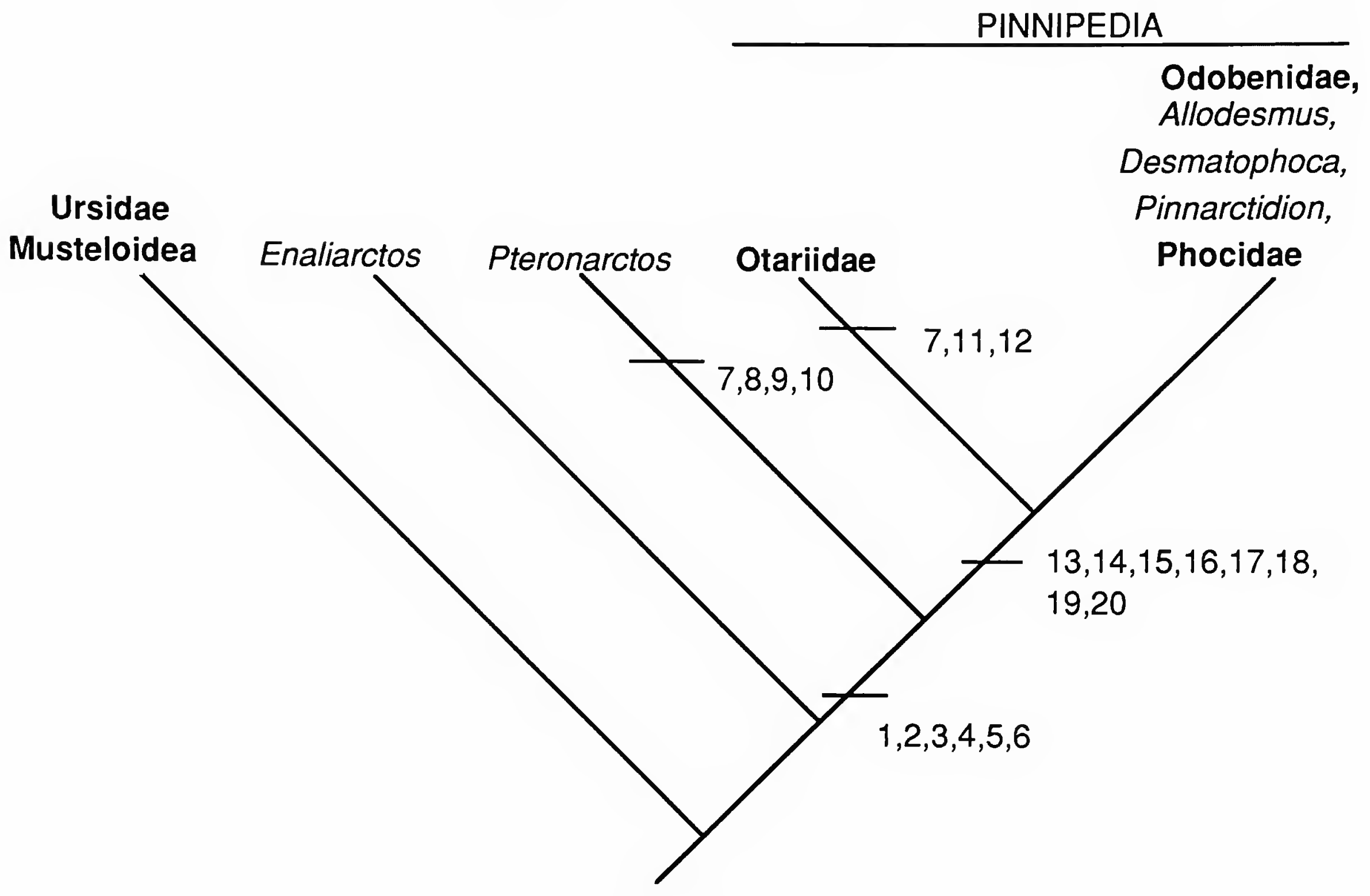

FIGURE 21.-Phylogeny of Pteronarctos and the Pinnipedia.

Pinnarctidion is significantly different from that of Pteronarctos (and "Pacificotaria"). In Pinnarctidion the mastoid and paroccipital processes are separated and not broadly continuous (Bames, 1979) and do not form a broadly continuous ridge as in Pteronarctos (and "Pacificotaria"). As observed here, there is variation in cheek tooth size among Pteronarctos species. Pteronarctos and Pinnarctidion are identified as sister taxa by Barnes (1992, fig. 10) supported by a single character, palate relatively flat. As noted in this study, additional specimens referred to $P$. goedertae show variation in this character.

According to Bames (1989) Pteronarctos is closest to the ancestry of the family "Otariidae" in which he includes otariids and odobenids plus their fossil relatives (= "Otarioidea"). Wyss (1987) argued for rejection of the "Otarioidea" identifying it as an artificial group based largely on primitive characters. This view of a non-monophyletic "Otarioidea" has been supported by the phylogenetic analyses of Berta et al. (1989), Berta and Ray (1990), Berta (1991), and Berta and Wyss (in press). Barnes (1989) enumerated 20 osteological characters as otariid synapomorphies. Berta and Wyss (in press) reviewed these characters and divided them into four categories: (1) characters for which the reported derived state occurs in relevant outgroups and are likely primitive; (2) characters for which the derived state also occurs in phocids; (3) characters in which the descriptions are problematic; and (4) characters in which the descriptions require modification. Our analysis of these characters, 17 out of 20 of which fell into categories 1 and 2, failed to reveal a single persuasive synapomorphy for the group. Thus we rejected the case for "otarioid" monophyly.

In determination of the phylogenetic relationship of Pteronarctos to other pinnipeds the distribution of 20 characters was considered (Appendices 1, 2). Enaliarctos was employed as the first outgroup and the Ursidae + musteloids as the second outgroup based on Berta and Wyss (in press). The data was subjected to a computer algorithm PAUP version 3.1.1 (Swofford, 1991) and all characters were entered as unordered. A single most parsimonious tree resulted with a tree length of 20 and a consistency index (C.I.) of 1.0 (Figure 21). Results of this analysis are summarized below. 
Pinnipediformes is a new name proposed here for the sister taxon of Enaliarctos. It comprises Pteronarctos and all its descendants, the Pinnipedia. This taxon is diagnosed by the following three unequivocal synapomorphies.

1. Mastoid process close to paroccipital process, the two connected by a high, continuous ridge. In ursids, other arctoids, and Enaliarctos the mastoid is connected to the paroccipital process by a low ridge. Pteronarctos, otariids, and odobenids show condition 1 in which a high continuous crest connects these processes.

2. Nasal processes of premaxillae prominent and protrude dorsal and anterior to incisor alveolar margin. As Howell (1929) first noted, in Zalophus there is a well defined process formed by the premaxillary tips that is absent in Phoca. As noted by Repenning and Tedford (1977), in Odobenus, owing to the highly modified snout region, the nasal processes are elevated well above the alveolar incisor region. Primitively otariids, odobenids, and phocids possess nasal processes as does Pteronarctos (Berta and Wyss, in press). Prominent nasal processes are lacking in ursids, Enaliarctos, Allodesmus, Desmatophoca, and phocids.

Judging from this distribution, prominent premaxillary nasal processes may serve to diagnose pinnipediformes with an apparent reversion to the primitive condition among phocoids.

3. Embrasure pit between $P^{4}$ and $M^{1}$ shallow or absent. Enaliarctos is distinguished from Pinnarctidion, Pteronarctos, and all other pinnipeds in its possession of a deep embrasure pit for the crown of $\mathrm{M}_{1}$ on the palate between $\mathrm{P}^{4}$ and $\mathrm{M}^{1}$ (Barnes, 1979, 1989).

Three additional synapomorphies are ambiguously assigned to this node including (4) reduced deciduous dentition; (5) maxilla makes significant contribution to orbital wall; and (6) lacrimal, fused early in ontogeny to maxilla and frontal, greatly reduced, or absent, does not contact jugal. Wyss (1987) noted that pinnipeds are unique among carnivorans in having the maxilla form a major contribution to the anterior orbital rim. Sutures in this region are not preserved in Enaliarctos. The adult male skull referred to Pteronarctos goedertae (USNM 335432) clearly shows the pinniped configuration of the maxilla. In addition this specimen also preserves the lacrimal, which although distinct does not contact the jugal. Because these characters are missing in Enaliarctos, I treat them as apomorphic of Pinnipedia, the minimum level at which observation confirms their distribution.

Pteronarctos is diagnosed by three unequivocal synapomorphies.

7. Slightly enlarged supraorbital process of the frontal. Pteronarctos displays larger supraorbital proccesses than Enaliarctos, as noted by Barnes (1989). These processes are variously modifed among pinnipeds.

8. $P^{3}$ with bilobed posterior root. Barnes (1989) originally diagnosed Pteronarctos by its possession of a bilobed posterior root on $\mathrm{P}^{3}$. In Enaliarctos the posterior root is separate.

9. $P^{4}$ with protocone root fused to posterolateral root. Pteronarctos is distinguished form Enaliarctos in having the protocone root fused to the posterolateral root rather than having a separate protocone root (Barnes, 1989).

Another derived character, (10) short lower cheek tooth row occurs in several otariids (i.e., Callorhinus, Otaria); a distribution that suggests independent aquisition in these taxa and Pteronarctos.

Three characters were identified as synapomorphies at the level of the Otariidae.

11. Frontals extend anteriorly between nasals. In otariids the frontals extend anteriorly between the nasals, forming a characteristic W-shape nasofrontal contact (King, 1983:151, fig. 6.4). It should be noted however, that in the holotype of Pteronarctos goedertae (Barnes, 1989, figs. 1, 2) and several referred skulls (LACM 127929, LACM 128002, USNM 167648) the frontals extend slightly between the nasals, which could be interpreted as incipient development of the derived condition.

7. Shelf-like supraorbital processes. The large shelflike supraorbital proceses of otariids are distinctive and especially well developed in adult males (Repenning and Tedford, 1977).

12. Secondary spine on scapula. An extra ridge is present in otariids, subdividing the supraspinous fossa (King, 1983). No secondary spine is present in odobenids or phocids. The presence of this spine can not be determined for Enaliarctos or Pteronarctos owing to poor preservation.

Eight characters are diagnostic of Pinnipedia (Otariidae, Odobenidae, Phocidae, Allodesmus, Desmatophoca, and Pinnarctidion). These are: (13) fossa muscularis absent; (14) antorbital processes large and well developed; (15) nasolabialis fossa absent; (16) pit for tensor tympani absent; (17) $\mathrm{P}^{4}$ protocone shelf reduced or absent; (18) $\mathrm{M}_{1}$ trigonid and talonid reduced or absent; (19) $\mathrm{M}_{2}$ absent; and (20) $\mathrm{I}^{3}$ lingual cingulum absent. For a more detailed discussion of more inclusive pinniped clades see Berta, 1991, and Berta and Wyss, in press.

\section{Conclusions}

Additional cranial material of the pinnipediform Pteronarctos goedertae is described from the Astoria Formation of coastal Oregon. This taxon is diagnosed by: slightly enlarged supraorbital processes; $\mathrm{P}^{3}$ with bilobed posterior roots; and $\mathrm{P}^{4}$ with protocone root fused to posterolateral root. Description of this new, larger sample of Pteronarctos and study of morphological variability in a modern pinniped population permits re-evaluation of the status of two previously described 
species, Pteronarctos piersoni and Pacificotaria hadromma. Evidence is presented for recognition of $P$. piersoni as the junior synonym of $P$. goedertae and for suppression of the genus Pacificotaria.

The temporal range of Pteronarctos encompasses the early
Miocene from approximately $19 \mathrm{Ma}$ to $15 \mathrm{Ma}$. Pteronarctos is removed from the paraphyletic "Enaliarctinae" and recognized as the closest relative of pinnipeds (including Otariidae, Odobenidae, Allodesmus, Desmatophoca, Pinnarctidion, and Phocidae). 


\section{Appendix 1}

\section{Pinniped Skeletal Features Discussed in Text}

(Symbols: 0 = primitive $1-4=$ derived conditions)

1. Mastoid process: close to paroccipital process, the two connected by a low ridge (0); or close to paroccipital process, the two connected by a high, continuous ridge (1).

2. Nasal processes of premaxilla: not prominent (0); or prominent, protrude dorsal and anterior to incisor alveolar margin (1).

3. Embrasure pit on palate between $P^{4}$ and $M^{l}$ : deep (0); or shallow (1); or absent (2).

4. Deciduous dentition: unreduced (0); or reduced (1).

5. Maxilla: excluded from contributing to orbital region by lacrimal, palatine, frontal, jugal, or a combination of these elements (0); or makes a significant contribution to orbital wall and forms anterior orbital rim (1).

6. Lacrimal: distinct, contacts jugal (0); or fusion early in ontogeny to maxilla and frontal, greatly reduced or absent, does not contact jugal (1).

7. Supraorbital processes: distinct, blunt (0); or reduced ridges (1); or enlarged ridges (2); or large, shelf-like (3); or absent (4).

8. $P^{3}$, bilobed roots: absent (0); or present (1).

9. $P^{4}$ : 3 rooted, separate protocone root $(0)$; or 2 rooted, protocone root transversely expanded and fused to posterolateral root (1); or 2-1 rooted, protocone root not transversely expanded (2).

10. Lower cheek tooth row: long (0); or short (1).

11. Frontals: do not extend anteriorly between nasals ( 0$)$; or extend anteriorly between nasals (1).

12. Scapula, secondary spine: absent (0); or present (1).

13. Fossa muscularis: present (0); or absent (1).

14. Antorbital process of the frontal: absent or small (0); or large and well developed (1).

15. Nasolabialis fossa: present (0); or absent (1).

16. Pit for tensor tympani: present (0); or absent (1).

17. $P^{4}$, protocone shelf: large $(0)$; or reduced-absent (1).

18. $M_{1}$, trigonid and talonid: subequal or lower than talonid (0); or suppressed (1).

19. $M_{2}$ : present (0); or absent (1).

20. $I^{3}$, lingual cingulum: present (0); or absent (1). 


\section{Appendix 2}

\section{Matrix Showing the Distribution of Skeletal Characters among Pinnipeds and Relevant Outgroups}

\begin{tabular}{l|l|c|c|c|c|c|c|c|c|c|c|c|c|c|c|c|c|c|c|c|c}
\multicolumn{2}{l}{} & 1 & 2 & 3 & 4 & 5 & 6 & 7 & 8 & 9 & 10 & 11 & 12 & 13 & 14 & 15 & 16 & 17 & 18 & 19 & 20 \\
\hline & & & & & & & & & & & & & & & & & & & & \\
\hline 1 & Ursidae-Musteloid & 0 & 0 & $0 / 1$ & 0 & 0 & 0 & 0 & 0 & 0 & 0 & 0 & 0 & $0 / 1$ & 0 & 0 & 0 & $0 / 1$ & 0 & 0 & 0 \\
\hline 2 & Enaliarctos & 0 & 0 & 0 & $?$ & $?$ & $?$ & 1 & 0 & 0 & 0 & 0 & $?$ & 0 & 0 & 0 & 0 & 0 & 0 & 0 & 0 \\
\hline 3 & Pteronarctos & 1 & 1 & 1 & $?$ & 1 & 1 & 2 & 1 & 1 & 1 & $0 / 1$ & $?$ & 0 & 0 & 0 & 0 & 0 & 0 & 0 & 0 \\
\hline 4 & Otariidae & 1 & 1 & 2 & 1 & 1 & 1 & 3 & 0 & 2 & $0 / 1$ & 1 & 1 & 1 & 1 & 1 & 1 & 1 & 1 & 1 & 1 \\
\hline 5 & Pinnipedia & 1 & 1 & 2 & 1 & 1 & 1 & $3 / 4$ & 0 & 2 & 0 & 0 & 0 & 1 & $0 / 1$ & 1 & 1 & 1 & 1 & 1 & 1
\end{tabular}




\section{Literature Cited}

Addicott, W.A.

1976. Neogene Molluscan Stages of Oregon and Washington. In A.E. Fritsche, H. Ter Best, Jr., and W.W., Wornardt, editors, The Neogene Symposium, pages 95-116. San Francisco: Society of Economic Paleontologists and Mineralogists [Annual Meeting, Pacific Section].

Armentrout, J.M.

1981. Correlation and Ages of Cenozoic Stratigraphic Units in Oregon and Washington. Geological Society of America, Special Paper, 184: 137-148.

Barnes, L.G.

1979. Fossil Enaliarctine Pinnipeds (Mammalia: Otariidae) from Pyramid Hill, Kern County, California. Contributions in Science, Natural History Museum of Los Angeles County, 318:1-41, figures 1-22.

1987. An Early Miocene Pinniped of the Genus Desmatophoca (Mammalia: Otariidae) from Washington. Contributions in Science, Natural History Museum of Los Angeles County, 382:1-20, figures 1-9.

1989. A New Enaliarctine Pinniped from the Astoria Formation, Oregon and a Classification of the Otariidae (Mammalia: Carnivora). Contributions in Science, Natural History Museum of Los Angeles County, 403:1-26, figures 1-9.

1990. A New Miocene Enaliarctine Pinniped of the Genus Pteronarctos (Mammalia: Otariidae) from the Astoria Formation, Oregon Contributions in Science, Natural History Museum of Los Angeles County, 422:1-20, figures 1-12.

1992. A New Genus and Species of Middle Miocene Enaliarctine Pinniped (Mammalia, Carnivora, Otariidae) from the Astoria Formation in Coastal Oregon. Contributions in Science, Natural History Museum of Los Angeles County. 431:1-27, figures 1-10.

Berta, A.

1991. New Fossils of Enaliarctos* (Pinnipedimorpha) from the Oligocene and Miocene of Oregon and the Role of "Enaliarctids" in Pinniped Phylogeny. Smithsonian Contributions to Paleobiology, 69:1-33, figures 1-22.

Berta, A., and C.E. Ray

1990. Skeletal Morphology and Locomotor Capabilities of the Archaic Pinniped, Enaliarctos mealsi. Journal of Vertebrate Paleontology, 10(2):141-157.

Berta, A., C.E. Ray, and A.R. Wyss

1989. Skeleton of the Oldest Known Pinniped, Enaliartos mealsi. Science, 244:60-62.
Berta, A., and A.R. Wyss

in press. Pinniped Phylogeny. Symposium on Marine Mammal Evolution. Proceedings of the San Diego Society of Natural History. Coombs, M.C.

1979. Tylocephalonyx, a New Genus of North American Dome-skulled Chalicotheres (Mammalia, Perissodactyla). Bulletin of the American Museum of Natural History, 164(1):1-64.

Howell, A.B.

1929. Contributions to the Comparative Anatomy of the Eared and Earless Seals (Genera Zalophus and Phoca). Proceedings of the United States National Museum, 73:1-42.

King, J.E.

1983. Seals of the World. Second edition, 240 pages. Ithaca, New York: Cornell University Press.

Moore, E.J.

1963. Miocene Marine Mollusks from the Astoria Formation in Oregon. Professional Papers of the United States Geological Survey, 419:1-109.

Munthe, J., and M.C. Coombs

1979. Miocene Dome-skulled Chalicotheres (Mammalia, Perissodactyla) from the Western United States: A Preliminary Discussion of a Bizarre Structure. Journal of Paleontology, 53(1):77-91.

Repenning, C.A., and R. H. Tedford

1977. Otarioid Seals of the Neogene. Professional Papers the United States Geological Survey, 992:1-93.

Simpson, G.G., A. Roe, and R.C. Lewontin

1960. Quantitative Zoology, Revised edition. 440 pages. New York: Harcourt, Brace, and Company.

Sivertson, E.

1954. A Survey of the Eared Seals (Family Otariidae) with Remarks on the Antarctic Seals Collected by M/K "Norvegia" in 1928-1929. Det

Swofford, D.L. Norske Vedenskaps-Akademii Oslo, 36:1-76, plates 1-10.

1991. (PAUP): Phylogenetic Analysis Using Parsimony, Version 3.1.1. Champaign, Illinois: Illinois Natural History Survey.

Wyss, A.

1987. The Walrus Auditory Region and Monophyly of Pinnipeds. American Museum Novitates, 2871:1-31. 




\section{REQUIREMENTS FOR SMITHSONIAN SERIES PUBLICATION}

Manuscripts intended for series publication receive substantive review (conducted by their originating Smithsonian museums or offices) and are submitted to the Smithsonian Institution Press with Form SI-36, which must show the approval of the appropriate authority designated by the sponsoring organizational unit. Requests for special treatment-use of color, foldouts, case-bound covers, etc.-require, on the same form, the added approval of the sponsoring authority.

Review of manuscripts and an by the Press for requirements of series format and style, completeness and clarity of copy, and arrangement of all material, as outlined below, will govern, within the judgment of the Press, acceptance or rejection of manuscripts and art.

Copy must be prepared on typewriter or word processor, double-spaced, on one side of standard white bond paper (not erasable), with $11 / 4^{\prime \prime}$ margins, submitted as ribbon copy (not carbon or xerox), in loose sheets (not stapled or bound), and accompanied by original ant. Minimum acceptable length is 30 pages.

Front matter (preceding the text) should include: title page with only title and author and no other information; abstract page with author, title, series, etc., following the established format; table of contents with indents reflecting the hierarchy of heads in the paper; also, foreword and/or preface, if appropriate.

First page of text should carry the title and author at the top of the page; second page should have only the author's name and professional mailing address, to be used as an unnumbered footnote on the first page of printed text.

Center heads of whatever level should be typed with initial caps of major words, with extra space above and below the head, but no other preparation (such as all caps or underline, except for the underline necessary for generic and specific epithets). Run-in paragraph heads should use period/dashes or colons as necessary.

Tabulations within text (lists of data, often in parallel columns) can be typed on the text page where they occur, but they should not contain rules or numbered table captions.

Formal tables (numbered, with captions, boxheads, stubs, rules) should be submitted as carefully typed, double-spaced copy separate from the text; they will be typeset unless otherwise requested. If camera-copy use is anticipated, do not draw rules on manuscript copy.

Taxonomic keys in natural history papers should use the aligned-couplet form for zoology and may use the multi-level indent form for botany. If cross referencing is required between key and text, do not include page references within the key, but number the keyed-out taxa, using the same numbers with their corresponding heads in the text.

Synonymy in zoology must use the short form (taxon, author, year:page), with full reference at the end of the paper under "Literature Cited." For botany, the long form (taxon, author, abbreviated journal or book title, volume, page, year, with no reference in "Literature Cited") is optional.

Text-reference system (author, year:page used within the text, with full citation in "Literature Cited" at the end of the text) must be used in place of bibliographic footnotes in all Contributions Series and is strongly recommended in the Studies Series: "(Jones, $1910: 122)$ " or "...Jones (1910:122)." If bibliographic footnotes are required, use the short form (author, brief title, page) with the full citation in the bibliography.

Footnotes, when fow in number, whether annotative or bibliographic, should be typed on separate sheets and inserted immediately atter the text pages on which the references occur. Extensive notes must be gathered together and placed at the end of the text in a notes section.

Bibliography, depending upon use, is termed "Literature Cited," "References," or "Bibliography." Spell out titles of books, articles, journals, and monographic series. For book and article titles use sentence-style capitalization according to the rules of the language employed (exception: capitalize all major words in English). For journal and series titles, capitalize the initial word and all subsequent words except articles, conjunctions, and prepositions. Transliterate languages that use a non-Roman alphabet according to the Library of Congress system. Underline (for italics) titles of journals and series and titles of books that are not part of a series. Use the parentheses/colon system for volume (number):pagination: "10(2):5-9." For alignment and arrangement of elements, follow the format of recent publications in the series for which the manuscript is intended. Guidelines for preparing bibliography may be secured from Series Section, SI Press.

Legends for illustrations must be submitted at the end of the manuscript, with as many legends typed, double-spaced, to a page as convenient.

Illustrations must be submitted as original art (not copies) accompanying, but separate from, the manuscript. Guidelines for prepaning art may be secured from the Series Section, SI Press. All types of illustrations (photographs, line drawings, maps, etc.) may be intermixed throughout the printed text. They should be termed Figures and should be numbered consecutively as they will appear in the monograph. If several illustrations are treated as components of a single composite figure, they should be designated by lowercase italic letters on the illustration; also, in the legend and in text references the italic letters (underlined in copy) should be used: "Figure 9b." Illustrations that are intended to follow the printed text may be termed Plates, and any components should be similarly lettered and referenced: "Plate 9b." Keys to any symbols within an illustation should appear on the art rather than in the legend.

Some points of style: Do not use periods after such abbreviations as "mm, $\mathrm{ft}$, USNM, NNE." Spell out numbers "one" through "nine" in expository text, but use digits in all other cases if possible. Use of the metric system of measurement is preferable; where use of the English system is unavoidable, supply metric equivalents in parentheses. Use the decimal system for precise measurements and relationships, common fractions for approximations. Use day/month/ year sequence for dates: "9 April 1976." For months in tabular listings or data sections, use three-letter abbreviations with no periods: "Jan, Mar, Jun," etc. Omit space between initials of a personal name: "J.B. Jones."

Arrange and paginate sequentially every sheet of manuscript in the following order: (1) title page, (2) abstract, (3) contents, (4) foreword and/or preface, (5) text, (6) appendices, (7) notes section, (8) glossary, (9) bibliography, (10) legends, (11) tables. Index copy may be submitted at page proof stage, but plans for an index should be indicated when the manuscript is submitted. 


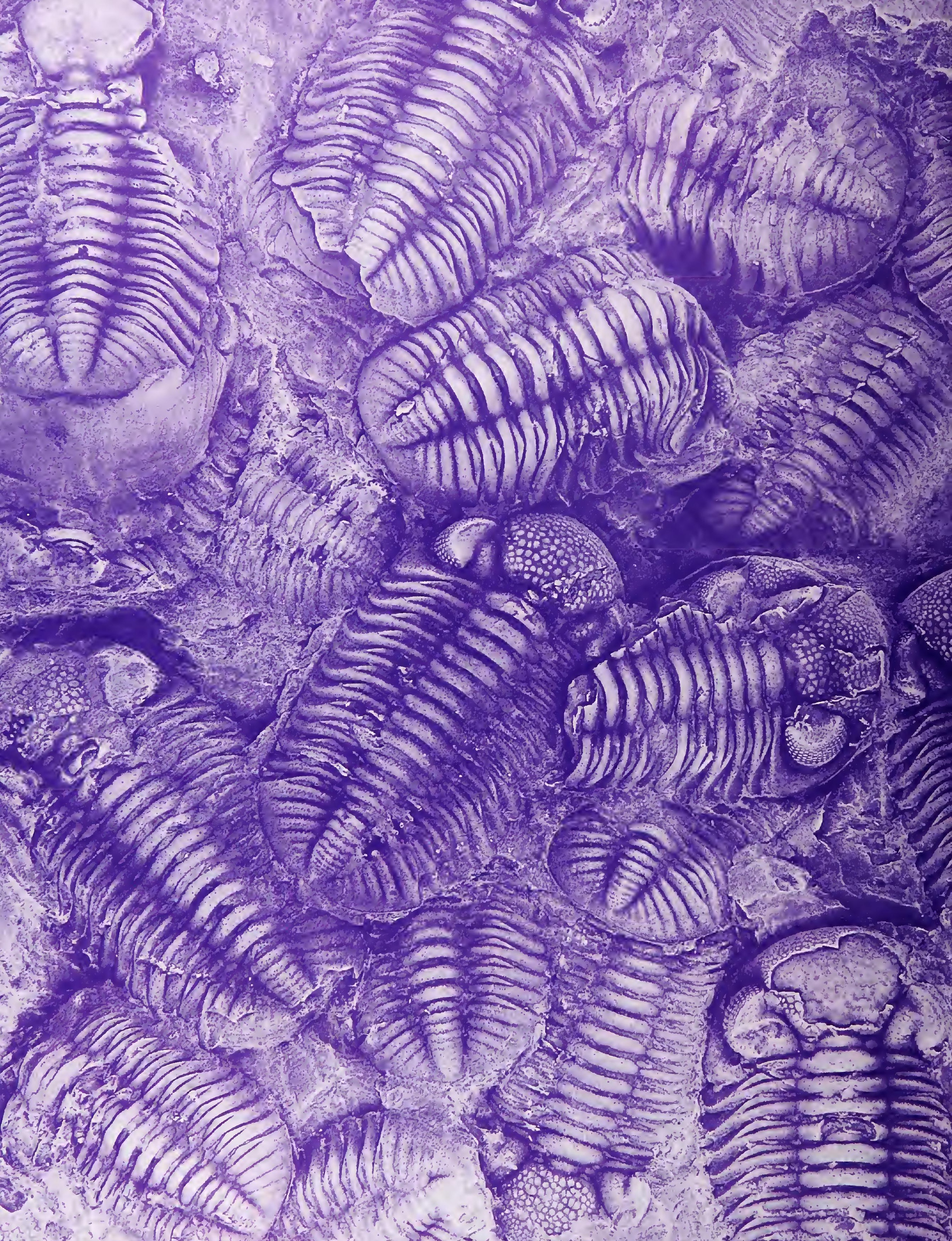

